\title{
Comparison of the measured and modeled electron densities, and electron and ion temperatures in the low-latitude ionosphere during 19-21 March 1988
}

\author{
A. V. Pavlov ${ }^{1}$, S. Fukao ${ }^{2}$, and S. Kawamura ${ }^{3}$ \\ ${ }^{1}$ Institute of Terrestrial Magnetism, Ionosphere and Radio-Wave Propagation, Russian Academy of Science (IZMIRAN), \\ Troitsk, Moscow Region, 142 190, Russia \\ ${ }^{2}$ Radio Science Center for Space and Atmosphere, Kyoto University, Kyoto, 611-0011, Japan \\ ${ }^{3}$ National Institute of Information and Communications Technology, 4-2-1, Nukui-kita, Koganei, Tokyo 184-8795, Japan
}

Received: 19 September 2003 - Revised: 9 March 2004 - Accepted: 30 March 2004 - Published: 7 September 2004

\begin{abstract}
We have presented a comparison between the modeled $\mathrm{NmF} 2$ and $\mathrm{hmF} 2$, and $\mathrm{NmF} 2$ and $\mathrm{hmF} 2$ which were observed at the equatorial anomaly crest and close to the geomagnetic equator simultaneously by the Akita, Kokubunji, Yamagawa, Okinawa, Chung-Li, Manila, Vanimo, and Darwin ionospheric sounders and by the middle and upper atmosphere (MU) radar at Shigaraki $\left(34.85^{\circ} \mathrm{N}, 136.10^{\circ} \mathrm{E}\right.$, Japan) during the 19-21 March 1988 geomagnetically quiet time period at moderate solar activity near approximately the same geomagnetic meridian of $201^{\circ}$. A comparison between the electron, $\mathrm{T}_{e}$, and ion, $\mathrm{T}_{i}$, temperatures measured by the $\mathrm{MU}$ radar and those produced by the model of the ionosphere and plasmasphere is presented for 19-21 March 1988. It is shown that there is a large disagreement between the measured and modeled hmF2 from about 07:00 UT to about 11:00 UT if the equatorial $\boldsymbol{E} \times \boldsymbol{B}$ drift given by Scherliess and Fejer (1999) is used. The required equatorial upward $\boldsymbol{E} \times \boldsymbol{B}$ drift is weaker from 03:14 UT to 11:14 UT than that given by Scherliess and Fejer (1999) for the studied time period. The required modification of the $\boldsymbol{E} \times \boldsymbol{B}$ drift weakens the effect of the fountain in $\mathrm{NmF} 2$ bringing the modeled and measured $\mathrm{hmF} 2$ and $\mathrm{NmF}$, into reasonable agreement. The depth of the equatorial $\mathrm{NmF} 2$ trough in the calculated $\mathrm{NmF} 2$ is approximately consistent with the measured depth if the modified equatorial $\boldsymbol{E} \times \boldsymbol{B}$ drift is used. It has been found that the north-south asymmetries in the observed $\mathrm{NmF} 2$ and hmF2 about the geomagnetic equator are mainly caused by the asymmetry in the neutral wind about the geomagnetic equator. In the Northern Hemisphere, the meridional neutral wind taken from the HWW90 wind model and the NRLMSISE-00 atomic oxygen density are corrected so that the model results agree with the ionospheric sounders and MU radar observations. A theory of the primary mechanisms causing the latitude dependence of the morning and evening peaks in $\mathrm{T}_{e}$ is developed. The latitude dependence of the magnitudes of these peaks in $\mathrm{T}_{e}$
\end{abstract}

Correspondence to: A. V. Pavlov

(pavlov@izmiran.rssi.ru) is interpreted in terms of the corresponding dependence of the electron density. The relative role of the $\boldsymbol{E} \times \boldsymbol{B}$ drift and the plasma drift caused by the neutral wind in the formation and the dependence of the magnitudes of the morning and evening electron temperature peaks on the geomagnetic latitude is studied.

Key words. Ionosphere (equatorial ionosphere; electric fields and currents; plasma temperature and density; ionosphere-atmosphere interactions; modeling and forecasting)

\section{Introduction}

The ionosphere at the geomagnetic equator and low geomagnetic latitudes has been studied observationally and theoretically for many years (see review papers presented by Moffett, 1979; Anderson, 1981; Walker, 1981; Bailey and Balan, 1996; Rishbeth, 2000; Abdu, 1997, 2001, and references therein). The low-latitude ionosphere undergoes dramatic changes as a result of changes in plasma motion perpendicular to the geomagnetic field, $\boldsymbol{B}$, due to an electric field, $\boldsymbol{E}$, which is generated in the E-region. This electric field affects F-region plasma, causing both ions and electrons to drift in the same direction with a drift velocity, $\boldsymbol{V}^{E}=\boldsymbol{E} \times \boldsymbol{B}$ $/ \mathrm{B}^{2}$. The zonal component of $\boldsymbol{V}^{E}$ (geomagnetic east- geomagnetic west component) is thought to have only a negligible effect on the low-latitude plasma densities (Anderson, 1981), but changes in the meridianal component (component in the plane of a geomagnetic meridian) of the $\boldsymbol{E} \times \boldsymbol{B}$ drift velocity, caused by changes in the zonal component, $E_{\Lambda}$, of the electric field, affect the distribution of plasma in the lowlatitude ionospheric F-region. The examination of the model of the meridional component of the drift velocity has been driven by the relationship between $\mathrm{E}_{\Lambda}$ and the dynamics of the F2-layer close to the geomagnetic equator. It is shown by Pavlov (2003) that the agreement between the measured 
and modeled F2-peak altitudes, hmF2, of the low-latitude ionosphere requires the correction of the empirical vertical drift model of Scherliess and Fejer (1999). The present work continues the study of the relationship between $\mathrm{E}_{\Lambda}$ and the dynamics of the low-latitude F2-layer in the present case study, in which $\mathrm{NmF} 2$ and $\mathrm{hmF} 2$ are observed simultaneously close to the same geomagnetic meridian at the geomagnetic longitudes of $201^{0} \pm 11^{\circ}$ by the Akita, Kokubunji, Yamagawa, Okinawa, Chung-Li, Manila, Vanimo, and Darwin ionospheric sounders and by the middle and upper atmosphere (MU) radar at Shigaraki $\left(34.85^{\circ} \mathrm{N}, 136.10^{\circ} \mathrm{E}\right.$, Japan) during the 19-21 March 1988 geomagnetically quiet time period at moderate solar activity.

The importance of diffusion, electrodynamic drift, and neutral wind on the generation and modulation of the equatorial anomaly in the electron density, $\mathrm{N}_{e}$, the plasma fountain and several fountain related features (an additional layer, a reverse fountain, an equatorial anomaly in vertical ionospheric electron content, a noon bite-out in $\mathrm{NmF} 2$, a nighttime increase in $\mathrm{N}_{e}$, plasma bubbles and spread $\mathrm{F}$ ) were studied by Balan and Bailey (1995) and Balan et al. (1997a). In the present work, we investigate the equatorial anomaly characteristics (the equatorial trough, and crest latitudes and magnitudes) from the comparison between the measured and modeled $\mathrm{N}_{e}$ and electron temperatures, $\mathrm{T}_{e}$, during 19-21 March 1988, using the new two-dimensional time dependent model of the low- and middle-latitude plasmasphere and ionosphere (Pavlov, 2003), which employs the updated rate coefficients of chemical reactions of ions and the updated $\mathrm{N}_{2}$, $\mathrm{O}_{2}$, and $\mathrm{O}$ photoionization and photoabsorption cross sections. The horizontal neutral wind drives the low-latitude Flayer plasma along magnetic field lines and causes significant north-south asymmetry in the equatorial ionization anomaly, producing notable effects on spread $\mathrm{F}$ generation and dynamics, and resulting in longitude dependent seasonal variability of $\mathrm{N}_{e}$ (Rishbeth, 1972, 2000; Balan and Bailey, 1995; Balan et al., 1997a, b; Abdu, 1997, 2001). We investigate the role of horizontal neutral winds in the ionization distribution, plasma dynamics, structuring, and thermal balance of the low-latitude ionosphere in the plane of the geomagnetic meridian of $201^{\circ}$ during 19-21 March 1988.

Ionospheric models are particularly valuable for investigating the changes that would result in observed quantities from changes in individual input parameters. The model of the ionosphere and plasmasphere of Pavlov (2003) uses the neutral temperature and densities as the model input. As a result, model/data discrepancies can arise due to a possible inability of the neutral atmosphere model to accurately predict the thermospheric response to the studied time period in the upper atmosphere. We investigate how well the MU radar data and the Akita, Kokubunji, Yamagawa, Okinawa, Chung-Li, Manila, Vanimo, and Darwin ionospheric sounder measurements of NmF2 taken during the 19-21 March 1988 geomagnetically quiet period agree with those calculated by the model of the ionosphere and plasmasphere using the NRLMSISE-00 model neutral temperature and densities given by Picone et al. (2002).
It follows from the electron, $\mathrm{T}_{e}$, and ion, $\mathrm{T}_{i}$, temperature profiles measured at Jicamarca that the enlargement of the altitude region with $\mathrm{T}_{e}>\mathrm{T}_{i}$ occurs at sunrise at all heights to at least $600 \mathrm{~km}$ (McClure, 1969). The diurnal variation of the low-latitude $\mathrm{T}_{e}$ is characterized by a morning peak (McClure, 1971; Oyama et al., 1996) and an evening peak (Fukao et al., 1991; Watanabe and Oyama, 1997). It is shown by Oyama et al. (1996) that the latitude dependence of the morning peak in $\mathrm{T}_{e}$ at $600 \mathrm{~km}$ for the June solstices at solar maximum is caused by the electron density latitude dependence due to a downward $\boldsymbol{E} \times \boldsymbol{B}$ plasma drift. Otsuka et al. (1998) found that the occurrence and strength of the morning and evening peaks in $\mathrm{T}_{e}$ over the $\mathrm{MU}$ radar depend on altitude, season, and solar activity under magnetically quiet conditions during 1986-1995. However, Otsuka et al. (1998) presented only a typical average picture of the diurnal electron temperature variations over the MU radar and did not compare the measured and modeled $\mathrm{T}_{e}$ over the $\mathrm{MU}$ radar for a specific time period. In this work, we study the latitude dependence of the occurrence and strength of the morning and evening peaks in $\mathrm{T}_{e}$ and the mechanisms causing these peaks in the low-latitude ionosphere during geomagnetically quiet time conditions of 19-21 March 1988 at moderate solar activity. The reliability of the conclusions is based on the comparison between the measured MU radar and modeled $\mathrm{T}_{e}$, and the use of the updated electron cooling rates (Pavlov, 1998 a, b; Pavlov and Berrington, 1999) in the model.

\section{Theoretical model}

The model of the low- and middle-latitude ionosphere and plasmasphere, which is described in detail by Pavlov (2003), calculates number densities, $\mathrm{N}_{i}$, of $\mathrm{O}^{+}\left({ }^{4} \mathrm{~S}\right), \mathrm{H}^{+}, \mathrm{NO}^{+}, \mathrm{O}_{2}^{+}$, $\mathrm{N}_{2}^{+}, \mathrm{O}^{+}\left({ }^{2} \mathrm{D}\right), \mathrm{O}^{+}\left({ }^{2} \mathrm{P}\right), \mathrm{O}^{+}\left({ }^{4} \mathrm{P}\right)$, and $\mathrm{O}^{+}\left({ }^{2} \mathrm{P}^{*}\right)$ ions, $\mathrm{N}_{e}, \mathrm{~T}_{e}$, and $\mathrm{T}_{i}$. As the model inputs, the horizontal components of the neutral wind are specified using the HWW90 wind model (Hedin et al., 1991), the model solar EUV fluxes are taken from the EUVAC model (Richards et al., 1994), while neutral densities and temperature are taken from the NRLMSISE-00 model (Picone et al., 2002).

Dipole orthogonal curvilinear coordinates $q$, $U$, and $\Lambda$ are used in the model calculations, where $\mathrm{q}$ is aligned with, and $\mathrm{U}$ and $\Lambda$ are perpendicular to, the magnetic field, and the $\mathrm{U}$ and $\Lambda$ coordinates are constant along a dipole magnetic field line. It should be noted that $\mathrm{q}=\left(\mathrm{R}_{E} / \mathrm{R}\right)^{2} \cos \Theta, \mathrm{U}=\left(\mathrm{R}_{E} / \mathrm{R}\right)$ $\sin ^{2} \Theta$, and $\Lambda$ is the geomagnetic longitude, where $R$ is the radial distance from the Earth's center, $\Theta=90^{\circ}-\varphi$ is the geomagnetic colatitude, $\varphi$ is the geomagnetic latitude, $\mathbf{R}_{E}$ is the Earth's radius. In the model, $\boldsymbol{V}^{E}=\mathrm{V}_{\Lambda}^{E} \boldsymbol{e}_{\Lambda}+\mathrm{V}_{U}^{E} \boldsymbol{e}_{U}$, where $\mathrm{V}_{\Lambda}^{E}=\mathrm{E}_{U} / \mathrm{B}$ is the zonal component of $\boldsymbol{V}^{E}, \mathrm{~V}_{U}^{E}=-\mathrm{E}_{\Lambda} / \mathrm{B}$ is the meridional component of $\boldsymbol{V}^{E}, \boldsymbol{E}=\mathrm{E}_{\Lambda} \boldsymbol{e}_{\Lambda}+\mathrm{E}_{U} \boldsymbol{e}_{U}, \mathrm{E}_{\Lambda}$ is the $\Lambda$ (zonal) component of $\boldsymbol{E}$ in the dipole coordinate system, $\mathrm{E}_{U}$ is the $\mathrm{U}$ (meridional) component of $\boldsymbol{E}$ in the dipole coordinate system, $\boldsymbol{e}_{\Lambda}$ and $\boldsymbol{e}_{U}$ are unit vectors in $\Lambda$ and $U$ directions, respectively, $\boldsymbol{e}_{U}$ is directed downward at the geomagnetic equator. 
Equations which determine the trajectory of the ionospheric plasma perpendicular to magnetic field lines and the moving coordinate system are derived by Pavlov (2003). The effects of the zonal (geomagnetic east-geomagnetic west) component of the $\boldsymbol{E} \times \boldsymbol{B}$ drift on $\mathrm{N}_{i}, \mathrm{~N}_{e}, \mathrm{~T}_{e}$, and $\mathrm{T}_{i}$ are not taken into account in the model calculations (Anderson, 1981). It means that the model works as a time dependent two-dimensional ( $q$ and $U$ coordinates) model of the ionosphere and plasmasphere. In this approximation, the trajectory of the ionospheric plasma in the $\mathrm{U}$ direction is found from the equation (Pavlov, 2003)

$\frac{\partial}{\partial t} U=-E_{\Lambda}^{\mathrm{eff}} R_{E}^{-1} B_{0}^{-1}$

where $\mathrm{E}_{\Lambda}^{\mathrm{eff}}=\mathrm{E}_{\Lambda} \mathrm{h}_{\Lambda} \mathrm{R}_{E}^{-1}, \mathrm{~h}_{\Lambda}=\mathrm{R} \sin \Theta, \mathrm{B}_{0}$ is the equatorial value of $\mathrm{B}$ for $\mathrm{R}=\mathrm{R}_{E}$ and $\Theta=0$.

The value of $E_{\Lambda}^{\text {eff }}$ is not changed along magnetic field lines, because the model takes into account that the magnetic field lines are "frozen" in the ionospheric and plasmaspheric plasma (Pavlov, 2003):

$$
\frac{\partial}{\partial q}\left(E_{\Lambda}^{\mathrm{eff}}\right)=0 \text {. }
$$

It should be noted that Eqs. (1)-(2) determine the changes in $\mathrm{E}_{\Lambda}$ along magnetic field lines and the altitude dependence of $\mathrm{E}_{\Lambda}$ in the ionosphere and plasmasphere.

In the model of the ionosphere and plasmasphere, the dependence of $\mathrm{E}_{\Lambda}$ on the solar local time, $\mathrm{t}_{g e}$, over the geomagnetic equator given by the dash-dotted line in Fig. 1 is obtained from the empirical F-region quiet time equatorial vertical drift velocity presented in Fig. 8 of Scherliess and Fejer (1999) for equinox conditions. As it will be discussed later in Sect. 4.1, this empirical equatorial zonal electric field is modified in the time range between 12:00 SLT and 24:00 SLT by the use of the comparison between the measured and modeled values of hmF2, where SLT is the solar local time at the geomagnetic equator for the geomagnetic longitude of $201^{\circ}$. The resulting equatorial magnitude of $\mathrm{E}_{\Lambda}\left(\mathrm{t}_{g e}\right)$, which is used in the model calculations, is shown by the solid line in Fig. 1. It should be noted that the procedure used to correct the $\boldsymbol{E} \times \boldsymbol{B}$ drift (comparing measured and modeled hmF2) is the same as that used by Balan et al. (1996). There are no MU radar vertical drift velocity measurements for the studied time period. We take into account that the perpendicular drifts over Arecibo and the MU radar for solstice seasons are similar (Takami et al., 1996). Therefore, the average quiet time value of $E_{\Lambda}$ at the F-region altitudes over Arecibo (dashed line in Fig. 1) is found from Fig. 2 of Fejer (1993), where the average quiet time perpendicular/northward F-region plasma drift for equinox conditions is presented and assumed to be similar to the value of $\mathrm{E}_{\Lambda}$ above the $\mathrm{MU}$ radar.

Equations (1-2) determine the trajectory of the ionospheric plasma perpendicular to magnetic field lines and the moving coordinate system. It follows from Eq. (1) that time variations of $U$ caused by the existence of the $E_{\Lambda}$ component of the electric field are determined by time variations of

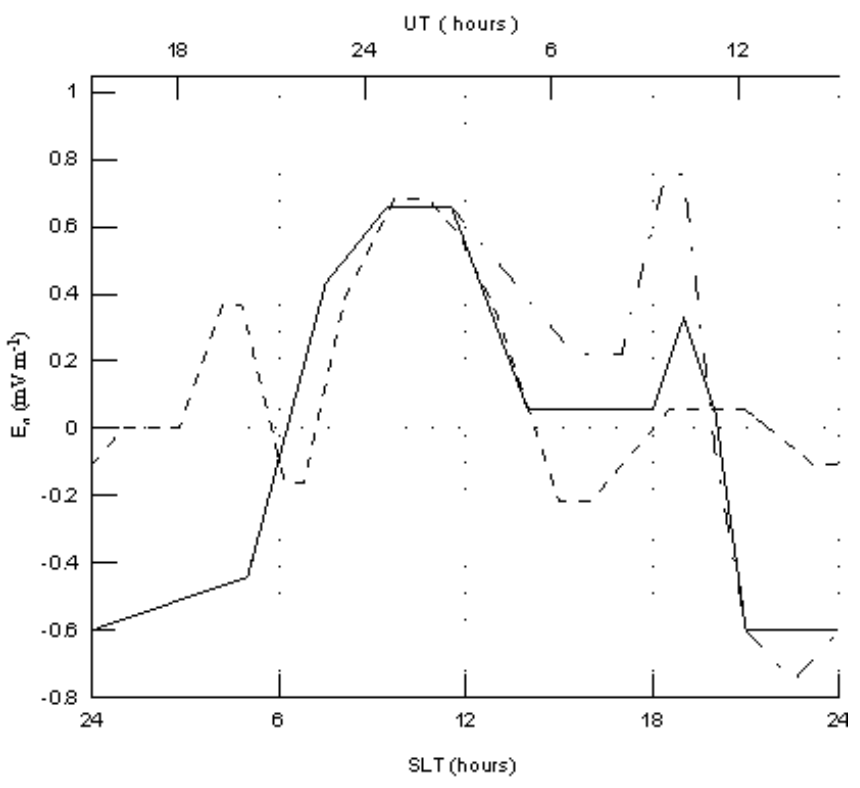

Fig. 1. Diurnal variations of $E_{\Lambda}$ during each day of 17-21 March 1988. The empirical F-region quiet time vertical drift velocity over the geomagnetic equator presented in Figure 8 of Scherliess and Fejer (1999) for equinox conditions was used for the equatorial value of $\mathrm{E}_{\Lambda}$ (dash-dotted line). The solid line shows the empirical equatorial electric field, which was modified in the time range between 12:00 SLT and 24:00 SLT by the use of the comparison between the measured and modeled hmF2. The dash-dotted line coincides with the solid line between 00:00 SLT and 12:00 SLT. The average quiet time value of $E_{\Lambda}$ at the F-region altitudes over Arecibo (dashed line) is found from the average quiet time perpendicular/northward F-region plasma drifts for equinox conditions presented in Fig. 2 of Fejer (1993). SLT is the local solar time at the geomagnetic equator and $201^{\circ}$ geomagnetic longitude.

$\mathrm{E}_{\Lambda}^{\text {eff }}$. We have to take into account Eq. (2), which shows that magnetic field lines are "frozen" in the ionospheric plasma. As a result, $E_{\Lambda}^{\text {eff }}(t)$ is not changed along magnetic field lines. The equatorial and Arecibo values of $\mathrm{E}_{\Lambda}\left(\mathrm{t}_{g e}\right)$ are used to find the equatorial and Arecibo values of $\mathrm{E}_{\Lambda}^{\mathrm{eff}}\left(\mathrm{t}_{g e}\right)$ from Eq. (2). The equatorial value of $\mathrm{E}_{\Lambda}^{\mathrm{eff}}\left(\mathrm{t}_{g e}\right)$ is used for magnetic field lines with an apex altitude, $\mathrm{h}_{a p}=\mathrm{R}_{e q}-\mathrm{R}_{E}$, less than $600 \mathrm{~km}$, where $\mathrm{R}_{e q}$ is the equatorial radial distance of the magnetic field line from the Earth's center and $\mathrm{R}_{E}$ is the Earth's radius. The Arecibo value of $E_{\Lambda}^{\text {eff }}\left(\mathrm{t}_{g e}\right)$ is used if the apex altitude is greater than $2126 \mathrm{~km}$. Linear interpolation of the equatorial and Arecibo values of $\mathrm{E}_{\Lambda}^{\mathrm{eff}}\left(\mathrm{t}_{g e}\right)$ is employed at intermediate apex altitudes.

The model calculates $\mathrm{N}_{i}, \mathrm{~N}_{e}, \mathrm{~T}_{i}$, and $\mathrm{T}_{e}$ in the fixed nodes of the fixed volume grid. This Eulerian computational grid consists of a distribution of the dipole magnetic field lines in the ionosphere and plasmasphere. One hundred dipole magnetic field lines are used in the model for each fixed value of $\Lambda$. The number of the fixed nodes taken along each magnetic field line is 191 . For each fixed value of $\Lambda$, the region of study is a $(q, U)$ plane, which is bounded by two dipole magnetic field lines. The low boundary magnetic field line 


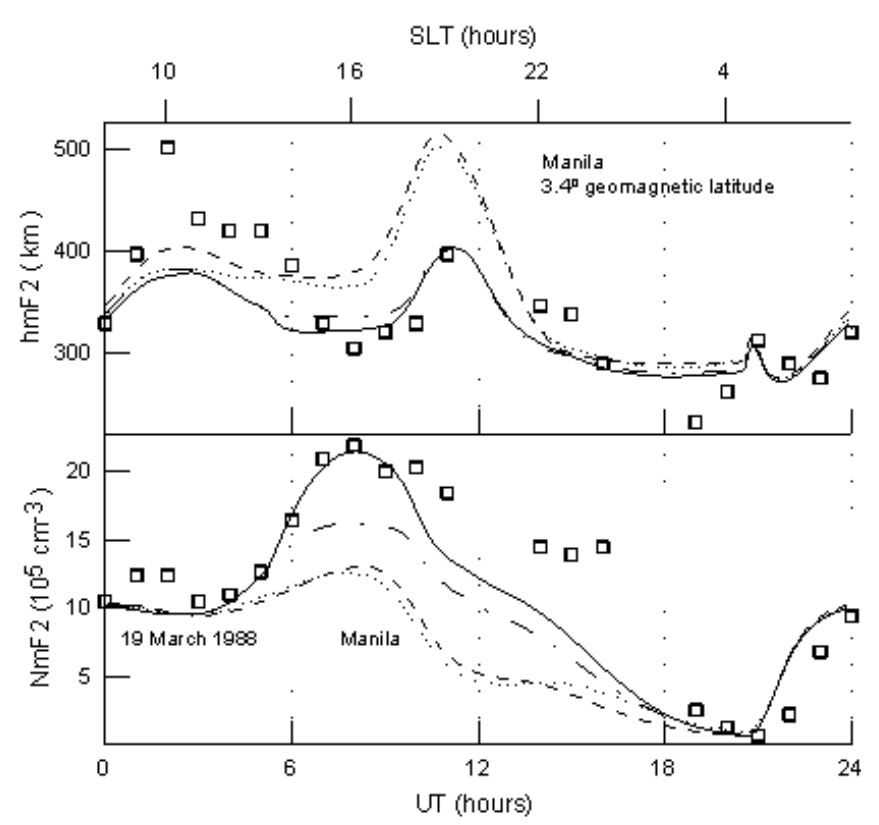

Fig. 2. Observed (squares) and calculated (lines) hmF2 (top panel) and NmF2 (bottom panel) on 19 March 1988. The model calculations have been carried out with different combinations of the model input parameters. The combinations are 1) the $\mathrm{SF}_{\Lambda}$, given by das-dotted line in Fig. 1, the NRLMSISE-00 neutral temperature and densities, and the HWW90 wind (dotted curves), 2) the $\mathrm{SF} \mathrm{E}_{\Lambda}$, the NRLMSISE-00 neutral temperature and densities, and the zero neutral wind (dashed curves), 3 ) the modified $\mathrm{E}_{\Lambda}$, given by solid line in Fig. 1, the NRLMSISE-00 neutral temperature and densities, and the HWW90 wind (dash-dot curves), and 4) the corrected equatorial $\mathrm{E}_{\Lambda}$, given by solid line in Fig. 1, the NRLMSISE00 neutral temperature and densities with the corrected value of [O], and the corrected HWW90 wind (solid curves). The corrections of the NRLMSISE-00 [O] and the HWW90 wind, are used to make the measured and modeled $\mathrm{NmF} 2$ and $\mathrm{hmF} 2$ agree over the MU radar and over all the ionosonde stations in Table 1. The NRLMSISE-00 model [O] was increased by a factor of 1.5 in the $0-15^{\circ}$ geomagnetic latitude range of the Northern Hemisphere from 05:14 UT to 09:44 UT. The meridional neutral wind, W, of the Northern Hemisphere, taken from the HWW90 wind model, was changed to $\mathrm{W}+\Delta \mathrm{W}$, where $\Delta \mathrm{W}=-30 \mathrm{~m} / \mathrm{sec}^{-1}$ between 10:14 UT and 13:44 UT during 17-21 March 1988, $\Delta \mathrm{W}=30 \mathrm{~m} / \mathrm{sec}^{-1}$ from 15:14 UT to 24:00 UT and from 00:00 UT to 00:14 UT during 1721 March 1988, $\Delta \mathrm{W}=20 \mathrm{~m} \mathrm{sec}^{-1}$ from 01:14 UT to 06:14 UT on 21 March 1988, and $\Delta \mathrm{W}=0$ from 00:14 UT to 09:14 UT during 17-21 March 1988 and from 07:14 UT to 09:14 UT on 21 March 1988. A linear interpolation between the values of $\Delta \mathrm{W}$ was used in the intermediate time periods. These values of $\Delta \mathrm{W}$ are used above the geomagnetic latitude of $24^{\circ}$, while $\Delta \mathrm{W}=0$ at the geomagnetic equator. A square interpolation of $\Delta \mathrm{W}$ is employed between $24^{\circ}$ and $0^{\circ}$.

has $\mathrm{h}_{a p}=150 \mathrm{~km}$. The upper boundary magnetic field line has $\mathrm{h}_{a p}=4491 \mathrm{~km}$ and intersects the Earth's surface at two middle-latitude geomagnetic latitudes: $\pm 40^{\circ}$. The computational grid dipole magnetic field lines are distributed between these two boundary lines. They have the interval, $\Delta \mathrm{h}_{a p}$, of $20 \mathrm{~km}$ between $\mathrm{h}_{a p}$ of the low boundary line and $\mathrm{h}_{p}$ of the nearest computational grid dipole magnetic field line. The value of $\Delta \mathrm{h}_{a p}$ is increased from $20 \mathrm{~km}$ to $45 \mathrm{~km}$ linearly as we go from the low computational grid boundary line to the upper computational grid dipole magnetic field line. We expect our finite-difference algorithm, which is described below, to yield approximations to $\mathrm{N}_{i}, \mathrm{~N}_{e}, \mathrm{~T}_{i}$, and $\mathrm{T}_{e}$ in the ionosphere and plasmasphere at discrete times $\mathrm{t}=0, \Delta \mathrm{t}, 2 \Delta \mathrm{t}$, with the time step $\Delta \mathrm{t}=10 \mathrm{~min}$. The model starts at 05:14 UT on 17 March. This UT corresponds to 14:00 SLT at the geomagnetic equator and $201^{\circ}$ geomagnetic longitude. The model is run from 05:14 UT on 17 March 1988 to 24:00 UT on 18 March 1988 before model results are used.

\section{Solar geophysical conditions and data}

The value of the geomagnetic $K_{p}$ index was between 0 and $2_{+}$for most of the studied time period of 19-21 March 1988, except between 09:00 and 12:00 UT on 20 March when the magnitude of $K_{p}$ was $3_{+}$. It should be noted that when the thermosphere is disturbed it takes time for it to relax back to its initial state, and this thermospheric relaxation time determines the time for the disturbed ionosphere to relax back to the quiet state. It means that not every time period with $K_{p} \leq 3$ can be considered as a magnetically quiet time period. The characteristic time of the neutral composition recovery after a storm impulse event ranges from 7 to $12 \mathrm{~h}$, on average (Hedin, 1987), while it may need up to days for all altitudes down to $120 \mathrm{~km}$ in the atmosphere to recover completely back to the undisturbed state of the atmosphere (Richmond and Lu, 2000). The value of $K_{p}$ was between 0 and $3_{0}$ for the previous 17-18 March 1988 time period, i.e. the studied time period of 19-21 March 1988 can be considered as a quiet time period. The F10.7 solar activity index was 116-118, while the 81-day averaged F10.7 solar activity index was 107.

The middle and upper atmosphere (MU) radar at Shigaraki, which is located at the geomagnetic latitude of $24.5^{\circ}$ and the geomagnetic longitude of $203.2^{\circ}$, operated from 00:00 SLT on 19 March to 07:00 SLT on 22 March. The capabilities of the radar for incoherent scatter observations have been described and compared with those of other incoherent scatter radars by Sato et al. (1989) and Fukao et al. (1990). Rishbeth and Fukao (1995) reviewed the MU radar studies of the ionosphere and thermosphere. The data that we use in this work are the measured time variations of altitude profiles of the electron density and temperature, and the ion temperature between $200 \mathrm{~km}$ and $600 \mathrm{~km}$ over the MU radar.

We use hourly critical frequencies, fof 2 and foE, of the $\mathrm{F} 2$ and $\mathrm{E}$ layers, and maximum usable frequency parameter, M(3000)F2, data from the Akita, Kokubunji, Yamagawa, Okinawa, Chung-Li, Manila, Vanimo, and Darwin ionospheric sounder stations available at the Ionospheric Digital Database of the National Geophysical Data Center, Boulder, Colorado. The locations of these ionospheric sounder stations and the location of the MU radar are shown in Table 1. The sounders and the MU radar are 
Table 1. Ionosonde station and radar names and locations.

\begin{tabular}{lrrrr}
$\begin{array}{l}\text { Ionosonde station and } \\
\text { radar names }\end{array}$ & $\begin{array}{r}\text { Geographic } \\
\text { latitude }\end{array}$ & $\begin{array}{r}\text { Geographic } \\
\text { longitude }\end{array}$ & $\begin{array}{r}\text { Geomagnetic } \\
\text { latitude }\end{array}$ & $\begin{array}{r}\text { Geomagnetic } \\
\text { longitude }\end{array}$ \\
\hline Akita & 39.7 & 140.1 & 29.6 & 206.2 \\
Kokubunji & 35.7 & 139.5 & 25.6 & 206.2 \\
Yamagawa & 31.2 & 130.6 & 20.5 & 198.6 \\
Okinawa & 26.3 & 127.8 & 15.4 & 196.3 \\
Chung-Li & 24.9 & 121.2 & 13.7 & 190.3 \\
Manila & 14.6 & 121.1 & 3.4 & 190.6 \\
Vanimo & -2.7 & 141.3 & -12.4 & 211.9 \\
Darwin & -12.4 & 130.9 & -23.0 & 202.0 \\
MU radar & 34.9 & 136.1 & 24.5 & 203.2 \\
\hline
\end{tabular}

within $\pm 11^{\circ}$ geomagnetic longitude of one another. As a result, all model simulations are carried out for the geomagnetic longitude of $201^{\circ}$. The values of the peak density, NmF2, of the F2 layer is related to the critical frequency fof 2 as $\mathrm{NmF} 2=1.24 \cdot 10^{10}$ fof $2^{2}$, where the unit of $\mathrm{NmF} 2$ is $\mathrm{m}^{-3}$, the unit of fof 2 is $\mathrm{MHz}$. To determine the ionosonde values of $\mathrm{hmF} 2$, we use the relation between hmF2 and the values of $\mathrm{M}(3000) \mathrm{F} 2$, fof2, and foE recommended by Dudeney (1983) from the comparison of different approaches as $\mathrm{hmF} 2=1490 /[\mathrm{M}(3000) \mathrm{F} 2+\Delta \mathrm{M}]-176$ where $\Delta \mathrm{M}=0.253 /($ fof $2 /$ foE- 1.215$)-0.012$. If there are no foE data then it is suggested that $\Delta \mathrm{M}=0$, i.e. the $\mathrm{hmF} 2$ formula of Shimazaki (1955) is used.

\section{Results}

\subsection{Equatorial perpendicular electric field modification}

At middle-latitudes, hmF2 is mainly determined by variations of thermospheric wind, while close to the geomagnetic equator, $\mathrm{hmF} 2$ is largely controlled by variations in the $\boldsymbol{E} \times \boldsymbol{B}$ drift (Rishbeth, 2000; Souza et al., 2000). As a result, it is necessary to compare the measured and modeled hmF2 close to the geomagnetic equator to evaluate the accuracy of the equatorial $\mathrm{E}_{\Lambda}$ given by the equatorial perpendicular plasma drift model of Scherliess and Fejer (1999) for the studied time period (this modeled $\mathrm{E}_{\Lambda}$ is labeled as the $\mathrm{SF} \mathrm{E}_{\Lambda}$ in this work).

The measured (squares) and calculated (lines) NmF2 (bottom panel) and hmF2 (top panel) are displayed in Fig. 2 for the 19 March 1988 time period above the Manila ionosonde station, which is very close to the geomagnetic equator (see Table 1). The combinations of the model input parameters are 1) the SF equatorial $\mathrm{E}_{\Lambda}$, the NRLMSISE-00 neutral temperature and densities, and the HWW90 wind (dotted curves), 2) the SF equatorial $\mathrm{E}_{\Lambda}$, the NRLMSISE-00 neutral temperature and densities, and no wind (dashed curves), 3) the corrected equatorial $E_{\Lambda}$ given by the solid line in Fig. 1, the NRLMSISE-00 neutral temperature and densities, and the HWW90 wind (dash-dot curves), and 4) the corrected equatorial $\mathrm{E}_{\Lambda}$ given by the solid line in Fig. 1, the NRLMSISE-00 neutral temperature and densities with the corrected value of [O], and the corrected HWW90 wind (solid curves). The corrections of the NRLMSISE-00 [O] and the HWW90 wind which are used in this work, allow the measured and modeled $\mathrm{NmF} 2$ and $\mathrm{hmF} 2$ to agree over the MU radar and over all the ionosonde stations of Table 1, as will be explained in Sect. 4.2.

The comparison between the measured hmF2 and the calculated results shown by the dotted and dashed lines in the upper panel of Fig. 2 clearly indicates that there is a large disagreement between the measured and modeled $\mathrm{hmF} 2$ from about 07:00 UT to about 11:00 UT on 19 March 1988 if the equatorial upward $\boldsymbol{E} \times \boldsymbol{B}$ drift given by Scherliess and Fejer (1999) is used. By comparing the results of calculations 1 and 2, it can be seen that we are not capable of making the measured and modeled hmF2 agree by the change in the neutral wind. A comparison of results 2 and 4 provide evidence that we can improve the agreement between the measured and modeled NmF2 using the corrected NRLMSISE$00[\mathrm{O}]$. However, these changes in the NRLMSISE-00 [O] do not lead to considerable variations in $\mathrm{hmF} 2$. Our calculations also show that the correction of the NRLMSISE-00 model $\left[\mathrm{N}_{2}\right]$, or $\left[\mathrm{O}_{2}\right]$ does not bring the measured and modeled hmF2 into agreement. Calculations 3 and 4 reproduce the observed features of hmF2 on 19 March 1988. The agreement between the measured and modeled hmF2 suggests that the corrected equatorial $\mathrm{E}_{\Lambda}$ given by the solid line in Fig. 1 is reasonable and can be used in the model calculations presented in this work. We conclude that the required equatorial upward $\boldsymbol{E} \times \boldsymbol{B}$ drift is weaker from 03:14 UT to 11:14 UT than that given by Scherliess and Fejer (1999) for the studied time period and this leads to the disagreement between the measured and modeled hmF2. The resulting correction in the equatorial upward $\boldsymbol{E} \times \boldsymbol{B}$ drift can be the result of considerable day-to-day variability in the equatorial electrojet (Rishbeth, 2000). It should be noted that the Jicamarca vertical $\boldsymbol{E} \times \boldsymbol{B}$ plasma drifts are most variable over a period of about 4 weeks, centered on the March equinox (Fejer and Scherliess, 2001), i.e. the equatorial $\boldsymbol{E} \times \boldsymbol{B}$ drift patterns of Scherliess and Fejer (1999) describe only average diurnal changes 


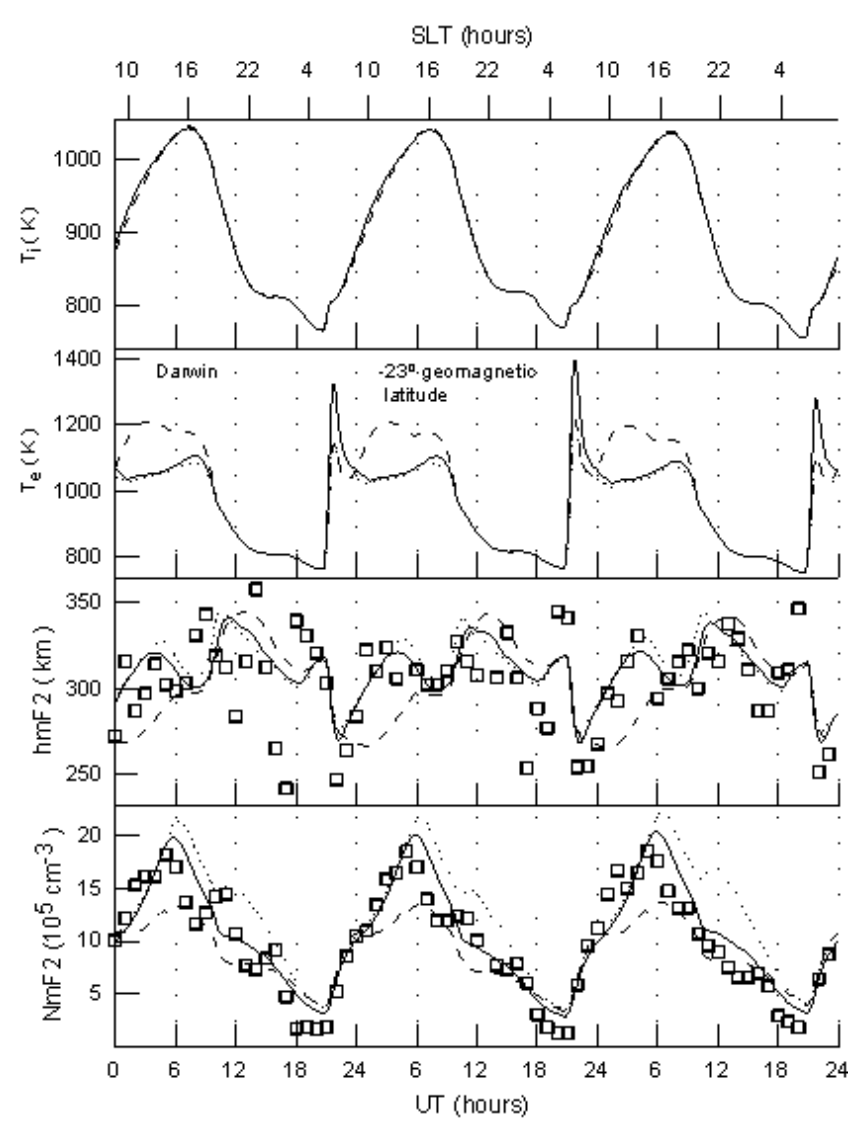

Fig. 3. Observed (squares) and calculated (lines) $\mathrm{NmF} 2$ and hmF2 (two lower panels), and electron and $\mathrm{O}^{+}$ion temperatures (two upper panels) at the F2-region main peak altitude above the Darwin ionosonde station during 19-21 March 1988. SLT is the solar local time at the Darwin ionosonde station. The results obtained from the model of the ionosphere and plasmasphere using the $\mathrm{SF}_{\Lambda}$, given by dash-dotted line in Fig. 1, the NRLMSISE-00 neutral temperature and densities, and the HWW90 wind as the input model parameters are shown by dotted lines. Solid lines show the results given by the model with the corrected equatorial $\mathrm{E}_{\Lambda}$, given by the solid line in Fig. 1, the corrected HWW90 wind, and the NRLMSISE00 model with the corrected value of [O]. In the modification of the meridional wind in the Northern Hemisphere, the meridional HWW90 wind was decreased by $30 \mathrm{~m} \mathrm{sec}^{-1}$ between 10:14 UT and 13:44 UT and was increased by $30 \mathrm{~m} \mathrm{sec}^{-1}$ from 15:14 UT to 24:00 UT. The NRLMSISE-00 model [O] was increased by a factor of 1.5 in the $0-15^{\circ}$ geomagnetic latitude range of the Northern Hemisphere from 05:14 UT to 09:44 UT. The results shown by dashed lines were calculated by the model with the same corrections of the NRLMSISE-00 [O] and meridional HWW90 wind as for the solid lines and when the value of the corrected $\mathrm{E}_{\Lambda}$, used in producing results shown by the solid lines, was divided by a factor of 10 at all the studied geomagnetic latitudes.

in the equatorial $\boldsymbol{E} \times \boldsymbol{B}$ drift (see very large scattering in the measured vertical plasma drift in Figs. 1 and 2 of Scherliess and Fejer, 1999).

The equatorial daytime upward $\boldsymbol{E} \times \boldsymbol{B}$ drift resulting from $\mathrm{E}_{\Lambda}$ lifts upward the ionospheric electrons and ions, and this leads to the increase of $\mathrm{hmF} 2$ close to the geomagnetic equa- tor. Ions and electrons then diffuse downward along the magnetic field lines leading to the plasma "fountain". The effect on $\mathrm{NmF} 2$ depends on the competition between the electron density reduction caused by the plasma outflow and the electron density enhancement caused by the decrease in the loss rate of $\mathrm{O}^{+}\left({ }^{4} \mathrm{~S}\right)$ ions. Comparison between the results of calculations 1 and 3 or 1 and 4 shows that the increase in the equatorial daytime upward $\boldsymbol{E} \times \boldsymbol{B}$ drift leads to the decrease in $\mathrm{NmF} 2$, i.e. the $\mathrm{NmF} 2$ reduction caused by the plasma outflow is stronger than the enhancement in $\mathrm{NmF} 2$ caused by the decrease in the loss rate of $\mathrm{O}^{+}\left({ }^{4} \mathrm{~S}\right)$ ions.

\subsection{Comparison between the measured and modeled NmF2} and $\mathrm{hmF} 2$ in the geomagnetic meridian plane

The measured (squares) and calculated (lines) NmF2 and hmF2 are displayed in the two lower panels of Figs. 311 for 19-21 March 1988 above the Darwin (Fig. 3), Vanimo (Fig. 4), Manila (Fig. 5), Chung-Li (Fig. 6), Okinawa (Fig. 7), Yamagawa (Fig. 8), and Akita (Fig. 9) ionosonde stations, and above the MU radar (Fig. 10), while $\mathrm{T}_{e}$ and $\mathrm{T}_{i}$ at $\mathrm{hmF} 2$ above the sounders and the MU radar are presented in the two upper panels of these figures. Figure 11 shows the measured (squares) and calculated (lines) $\mathrm{N}_{e}$ (bottom panel), $\mathrm{T}_{e}$ (middle panel), and $\mathrm{T}_{i}$ (top panel) at the $400 \mathrm{~km}$ altitude above the MU radar. The latitude and longitude location of the Kokubunji sounder is very close to that of the MU radar and the calculated $\mathrm{hmF} 2, \mathrm{~N}_{e}, \mathrm{~T}_{e}$, and $\mathrm{T}_{i}$ above this sounder are practically the same as those in Fig. 10. The model results using the combinations of the $\mathrm{SF}_{\Lambda} \mathrm{E}_{\Lambda}$ given by dash-dotted line in Fig. 1, the NRLMSISE-00 neutral temperature and densities, and the HWW90 wind are shown by dotted lines. Solid lines show the results given by the model with the corrected equatorial $\mathrm{E}_{\Lambda}$ given by the solid line in Fig. 1, the corrected NRLMSISE-00 [O] (the value of [O] was increased by a factor of 1.5 in the $0-15^{\circ}$ geomagnetic latitude range of the Northern Hemisphere from 05:14 UT to 09:44 UT), and the corrected meridional neutral HWW90 wind. In the Northern Hemisphere, the meridional neutral wind, W, taken from the HWW90 wind model, was changed to $\mathrm{W}+\Delta \mathrm{W}$, where $\Delta \mathrm{W}=-30 \mathrm{~m} / \mathrm{sec}^{-1}$ between $10: 14 \mathrm{UT}$ and 13:44 UT during 17-21 March 1988, $\Delta \mathrm{W}=30 \mathrm{~m} / \mathrm{sec}^{-1}$ from 15:14 UT to 24:00 UT and from 00:00 UT to 00:14 UT during 17-21 March 1988, $\Delta \mathrm{W}=20 \mathrm{~m} / \mathrm{sec}^{-1}$ from 01:14 UT to 06:14 UT on 21 March 1988, and $\Delta \mathrm{W}=0$ from 00:14 UT to 09:14 UT during 17-21 March 1988 and from 07:14 UT to 09:14 UT on 21 March 1988. A linear interpolation between the values of $\Delta \mathrm{W}$ was used in the intermediate time periods. This additional meridional neutral wind is used in the model calculations above the geomagnetic latitude of $24^{\circ}$, while $\Delta \mathrm{W}=0$ at the geomagnetic equator. A square interpolation of $\Delta \mathrm{W}$ is employed between $24^{\circ}$ and $0^{\circ}$. Dashed lines were calculated by the model with the same corrections of the NRLMSISE-00 [O] and meridional neutral HWW90 wind as for solid lines and when the value of $\mathrm{E}_{\Lambda}$, used in producing results shown by the solid lines, was divided by a factor of 10 at all the studied geomagnetic latitudes. 


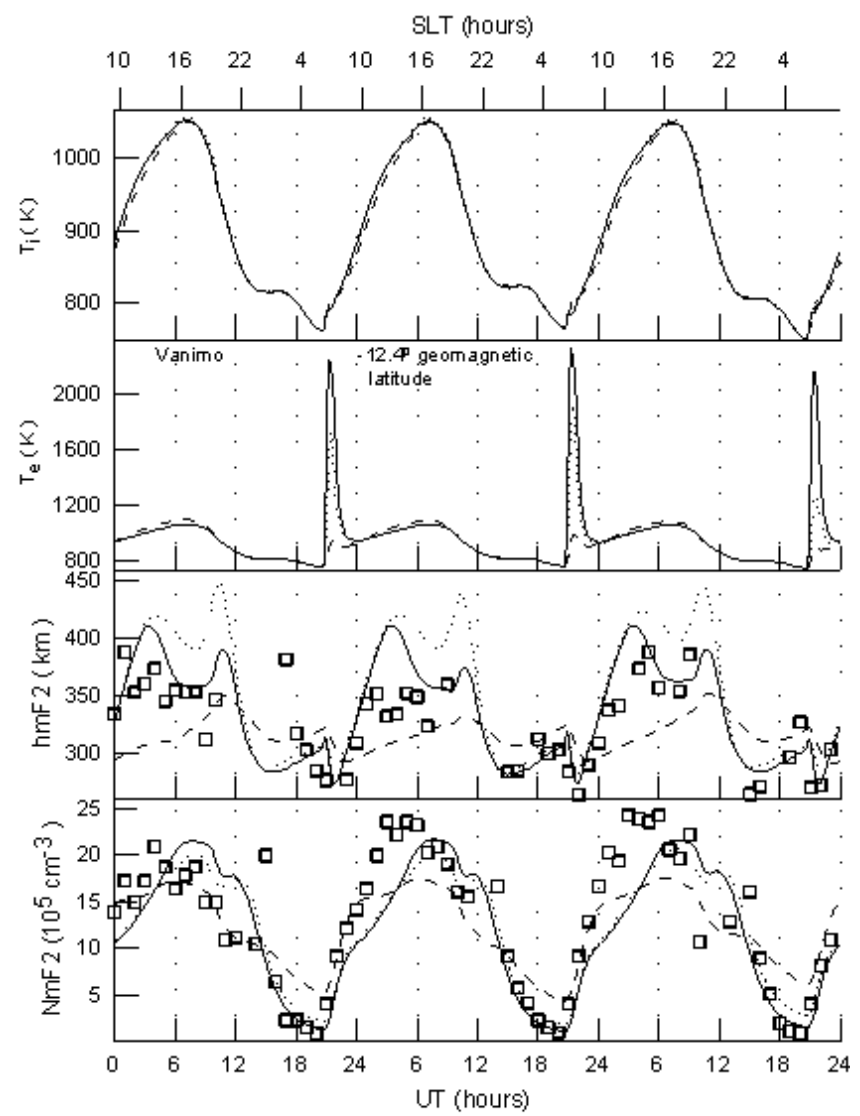

Fig. 4. From bottom to top, observed (squares) and calculated (lines) of $\mathrm{NmF} 2, \mathrm{hmF} 2$, electron temperatures and $\mathrm{O}^{+}$ion temperatures at the F2-region main peak altitude above the Vanimo ionosonde station during 19-21 March 1988. SLT is the solar local time at the Vanimo ionosonde station. The curves are the same as in Fig. 3.

By comparing dotted lines and squares in Figs. 4-6, it is seen that the calculated $\mathrm{hmF} 2$ is higher than the measured one from about 07:00 UT to about 11:00 UT on 19 March 1988 if the equatorial upward $\boldsymbol{E} \times \boldsymbol{B}$ drift given by Scherliess and Fejer (1999) is employed. Use of the corrected equatorial $\mathrm{E}_{\Lambda}$ given by the solid line in Fig. 1 brings the measured and modeled $\mathrm{hmF} 2$ into reasonable agreement, although there are some quantitative differences. On the other hand, it is well known (Su et al., 1997; Balan et al., 1998) that variations of $\mathrm{hmF} 2$ are controlled mainly by variations in the neutral wind and $\mathrm{E}_{\Lambda}$ for low mid-latitudes, where the MU radar and the Akita ionosonde station are located. However, the HWW90 wind velocities are known to differ from observations (Oliver et al., 1990). For the present study the model HWW90 winds are modified, as explained above, to bring the modeled $\mathrm{hmF} 2$ in reasonable agreement with $\mathrm{hmF} 2$ measured by the MU radar and the Akita ionosonde station (see solid lines in Figs. 9-11).

We can expect that the neutral models have some inadequacies in predicting the number densities with accuracy, and we have to change the number densities by correction

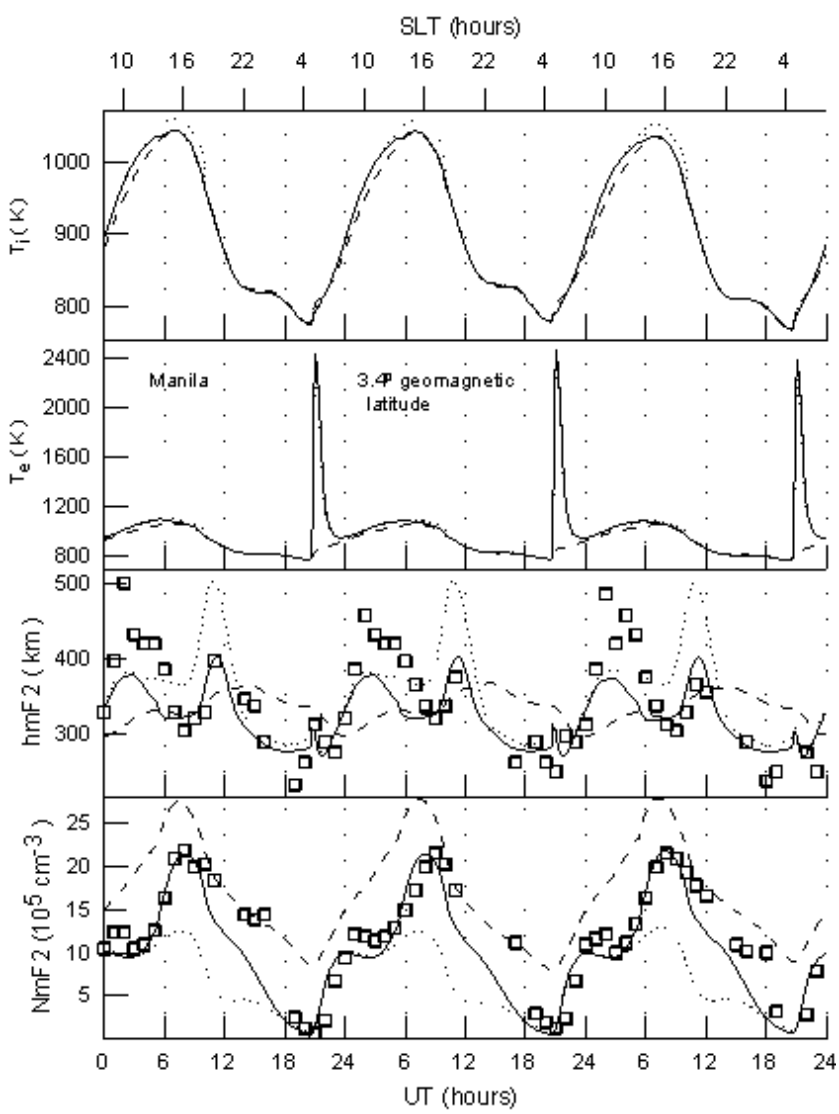

Fig. 5. From bottom to top, observed (squares) and calculated (lines) of $\mathrm{NmF} 2, \mathrm{hmF} 2$, electron temperatures and $\mathrm{O}^{+}$ion temperatures at the F2-region main peak altitude above the Manila ionosonde station during 19-21 March 1988. SLT is the solar local time at the Manila ionosonde station. The curves are the same as in Fig. 3.

factors at all altitudes to bring the modeled electron densities into agreement with the measurements. The value of $[\mathrm{O}]$ was increased by a factor of 1.5 in the $0-15^{\circ}$ geomagnetic latitude range of the Northern Hemisphere from 05:14 UT to 09:44 UT at all altitudes from the comparison between the modeled $\mathrm{NmF} 2$ and $\mathrm{NmF} 2$ measured by the Manila ionosonde station. One can see from Fig. 5 that the NRLMSISE-00 model with the modified [O] improves the agreement with the measured NmF2 over the Manila ionosonde station.

The NRLMSISE-00 model can have some inadequacies in predicting the actual $\left[\mathrm{N}_{2}\right]$ and $\left[\mathrm{O}_{2}\right]$ with accuracy. However, to reach the same agreement between the measured and modeled NmF2 over the Manila ionosonde station, the values of the NRLMSISE-00 $\left[\mathrm{N}_{2}\right]$ and $\left[\mathrm{O}_{2}\right]$ must be decreased by a factor of 2 in the $0-15^{\circ}$ geomagnetic latitude range of the Northern Hemisphere from 05:14 UT to 09:44 UT at all altitudes without NRLMSISE-00 [O] corrections. Thus, the comparison between the NRLMSISE-00 $\left[\mathrm{N}_{2}\right]$ and $\left[\mathrm{O}_{2}\right]$ decrease and the NRLMSISE-00 [O] increase does not show similarity and consistency in the magnitudes of their effects 


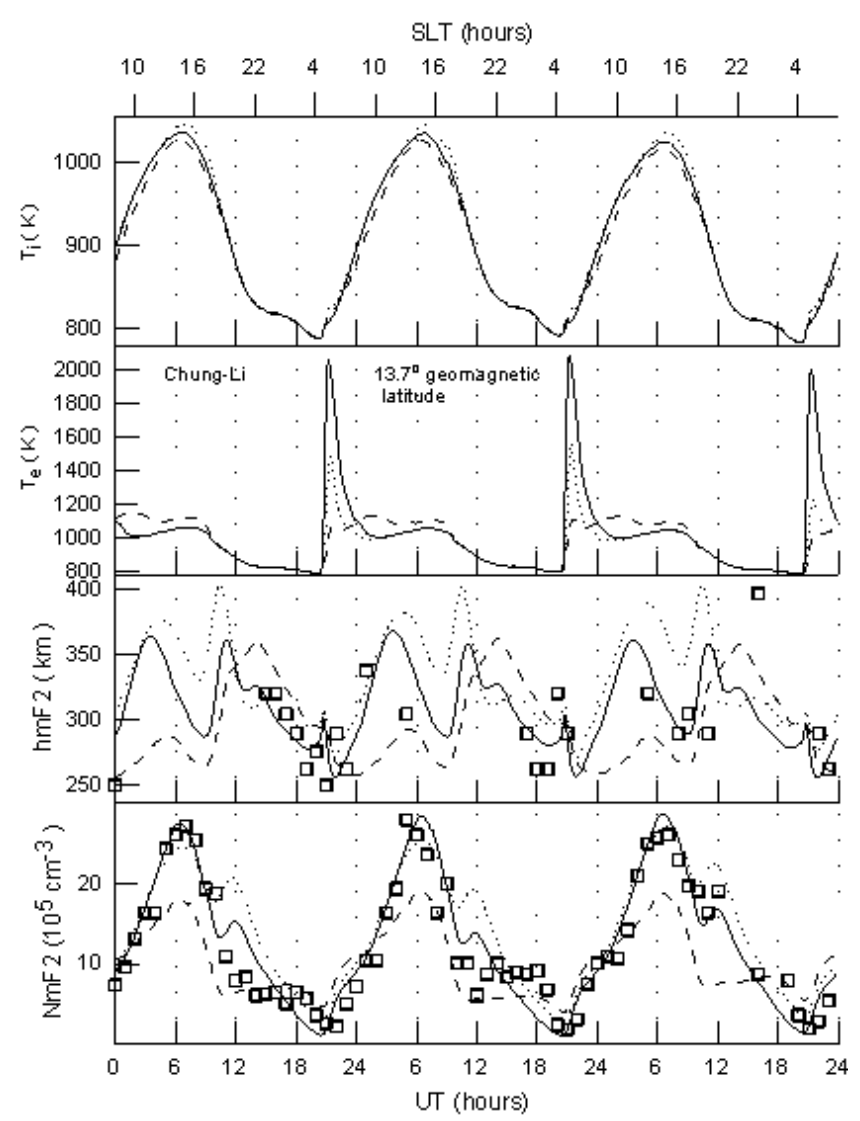

Fig. 6. From bottom to top, observed (squares) and calculated (lines) of $\mathrm{NmF} 2, \mathrm{hmF} 2$, electron temperatures and $\mathrm{O}^{+}$ion temperatures at the F2-region main peak altitude above the Chung-Li ionosonde station during 19-21 March 1988. SLT is the solar local time at the Chung-Li ionosonde station. The curves are the same as in Fig. 3.

on $\mathrm{NmF} 2$ close to the geomagnetic equator. This difference in the reaction of the calculated $\mathrm{NmF} 2$ is large enough to provide evidence in favor of increasing $[\mathrm{O}]$ in comparison with reducing $\left[\mathrm{N}_{2}\right]$ and $\left[\mathrm{O}_{2}\right]$.

The middle-latitude daytime F2 peak electron density is proportional to $[\mathrm{O}] /\left[\mathrm{N}_{2}\right]$ (e.g. Rishbeth and Garriot, 1969). In comparison with the middle-latitude ionosphere, the lowlatitude ionosphere is special because of the constraints imposed on electron and ion motions by the magnetic field and by the zonal component of the electric field. The model calculations of this work provide evidence that the dependence of $\mathrm{NmF} 2$ on $\left[\mathrm{N}_{2}\right]$ and $\left[\mathrm{O}_{2}\right]$ is weaker than the dependence of $\mathrm{NmF} 2$ on [O] by day at low geomagnetic latitudes. We conclude that $\mathrm{NmF} 2$ is not proportional to $[\mathrm{O}] /\left[\mathrm{N}_{2}\right]$ or to $[\mathrm{O}] /\left[\mathrm{O}_{2}\right]$ in the daytime ionosphere close to the geomagnetic equator.

The comparison between the measured (squares) and modeled (lines) $\mathrm{NmF} 2$ and $\mathrm{hmF} 2$ latitude variations is shown in Fig. 12 at 08:00 UT (two upper panels) and 11:00 UT (two lower panels) on 19 March 1988. The combinations of the model input parameters used in the calculations of the model

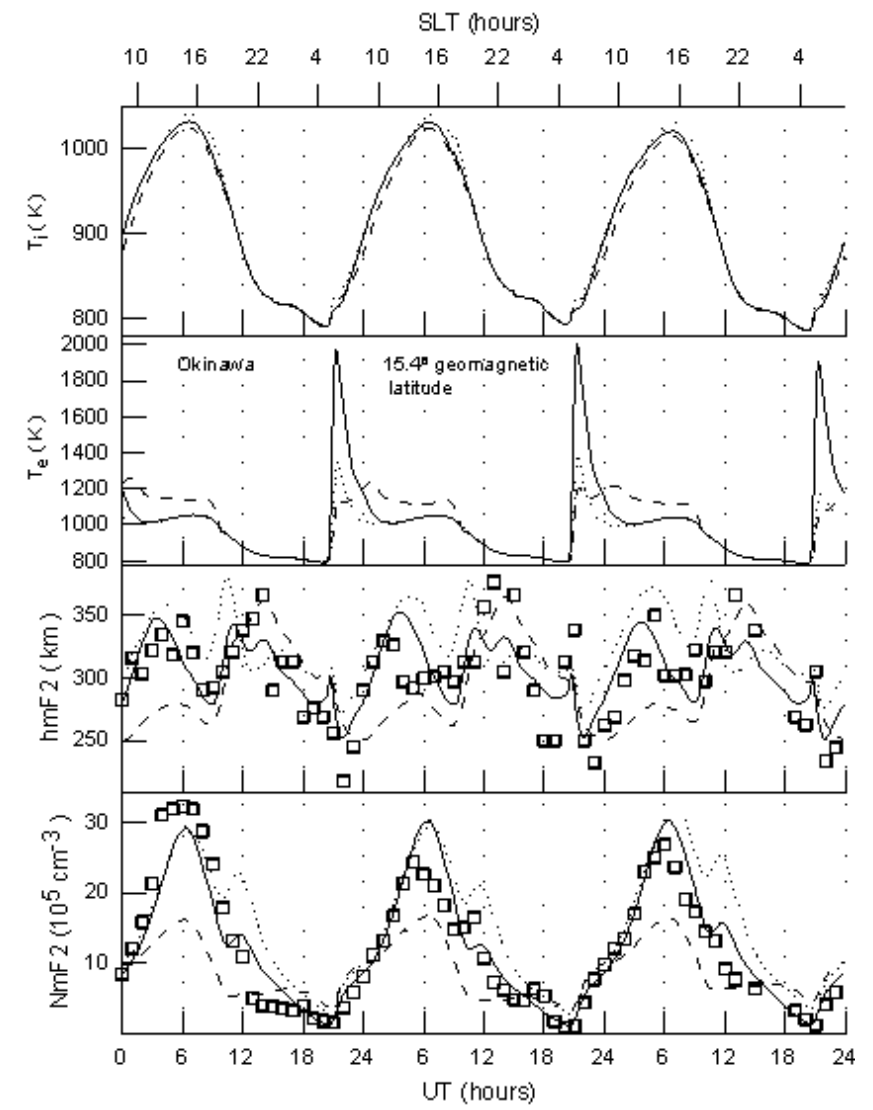

Fig. 7. From bottom to top, observed (squares) and calculated (lines) of $\mathrm{NmF} 2, \mathrm{hmF} 2$, electron temperatures and $\mathrm{O}^{+}$ion temperatures at the F2-region main peak altitude above the Okinawa ionosonde station during 19-21 March 1988. SLT is the solar local time at the Okinawa ionosonde station. The curves are the same as in Fig. 3.

results shown by the solid and the dotted lines are the same as those for solid and dotted lines in Figs. 3-11, respectively. The comparison between the measured hmF2, NmF2 and the calculated results shown by dotted lines clearly indicates that there is the disagreement between the measured and modeled hmF2 and NmF2 at low geomagnetic latitudes at 08:00 UT and 11:00 UT on 19 March 1988 if the equatorial upward $\boldsymbol{E} \times \boldsymbol{B}$ drift given by Scherliess and Fejer (1999) is used. Figure 12 shows that the modification of the equatorial upward $\boldsymbol{E} \times \boldsymbol{B}$ drift improves the agreement between the modeled and measured hmF2 and NmF2, and weakens the effect of the fountain in $\mathrm{NmF} 2$.

The model calculations produce the onset of the equatorial anomaly crest formation close to 02:00 UT, in agreement with the ionosonde measurements. The model calculations show that the crests disappear close to 15:00 UT. Figures 3-9 show that the NmF2 values were not determined from ionograms at some ionosonde stations from 12:00 UT to 15:00 UT, and there is scattering in the data for this time period. As a result, the time of the crest disappearance is unresolved from the measured $\mathrm{NmF} 2$. The principal feature of 


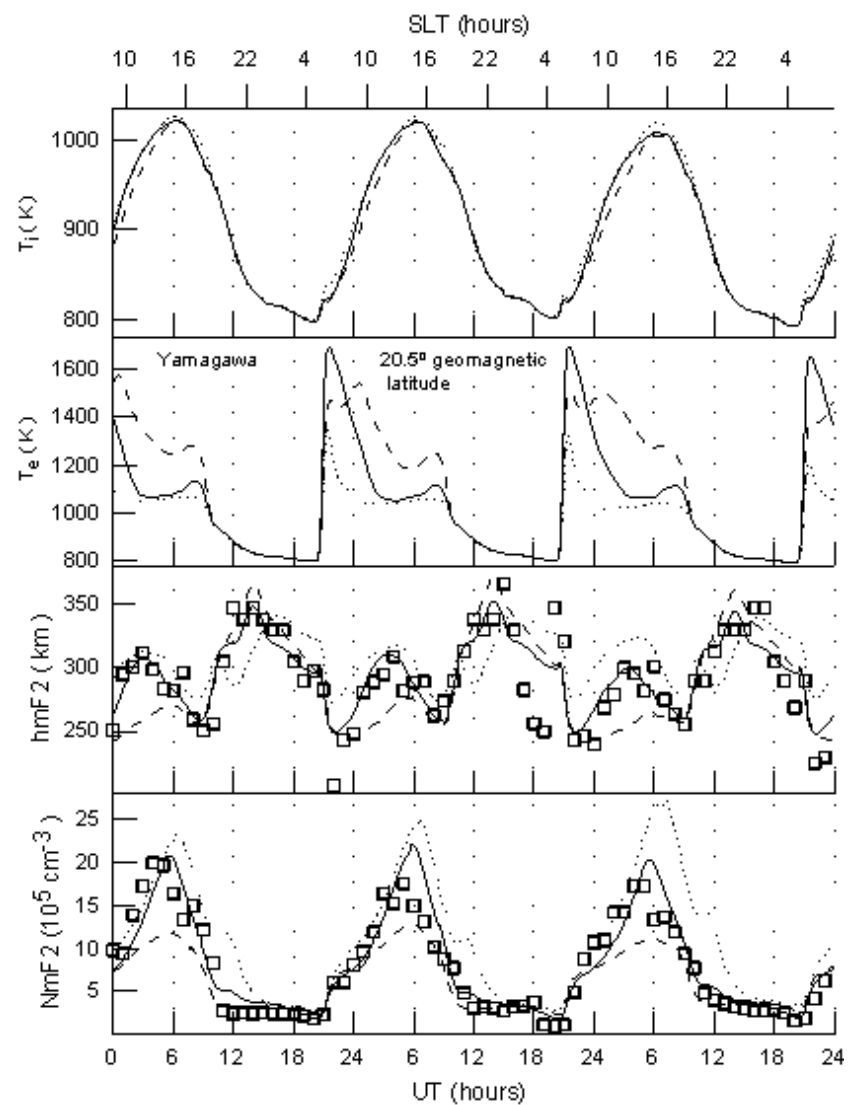

Fig. 8. From bottom to top, observed (squares) and calculated (lines) of $\mathrm{NmF} 2, \mathrm{hmF} 2$, electron temperatures and $\mathrm{O}^{+}$ion temperatures at the F2-region main peak altitude above the Yamagawa ionosonde station during 19-21 March 1988. SLT is the solar local time at the Yamagawa ionosonde station. The curves are the same as in Fig. 3 .

the equatorial anomaly is the crest-to-trough ratio. The measured and modeled NmF2 show that the equatorial anomaly effect is most pronounced close to 06:00 UT.

Figure 13 presents the comparison between the measured (squares) and modeled (lines) $\mathrm{NmF} 2$ and $\mathrm{hmF} 2$ latitude variations at 05:00 UT (two upper panels) and 06:00 UT (two lower panels) on 19 March 1988. The combinations of the model input parameters used in the calculations of the model results shown by the solid and dotted lines are the same as those for solid and dotted lines in Figs. 3-12, respectively. Dashed lines show the results produced by the model with the corrected equatorial $\mathrm{E}_{\Lambda}$ given by the solid line in Fig. 1, the NRLMSISE-00 neutral temperature and densities with the same correction of $[\mathrm{O}]$ as for the solid lines, and when the neutral wind is equal to zero.

The striking feature of the observed (squares) and modeled (solid and dotted lines) hmF2 and NmF2 is the existence of an asymmetry in $\mathrm{hmF} 2$ and $\mathrm{NmF} 2$ between the northern and southern geomagnetic hemispheres. The crest electron density is greater in the northern geomagnetic hemisphere than that in the southern geomagnetic hemisphere,

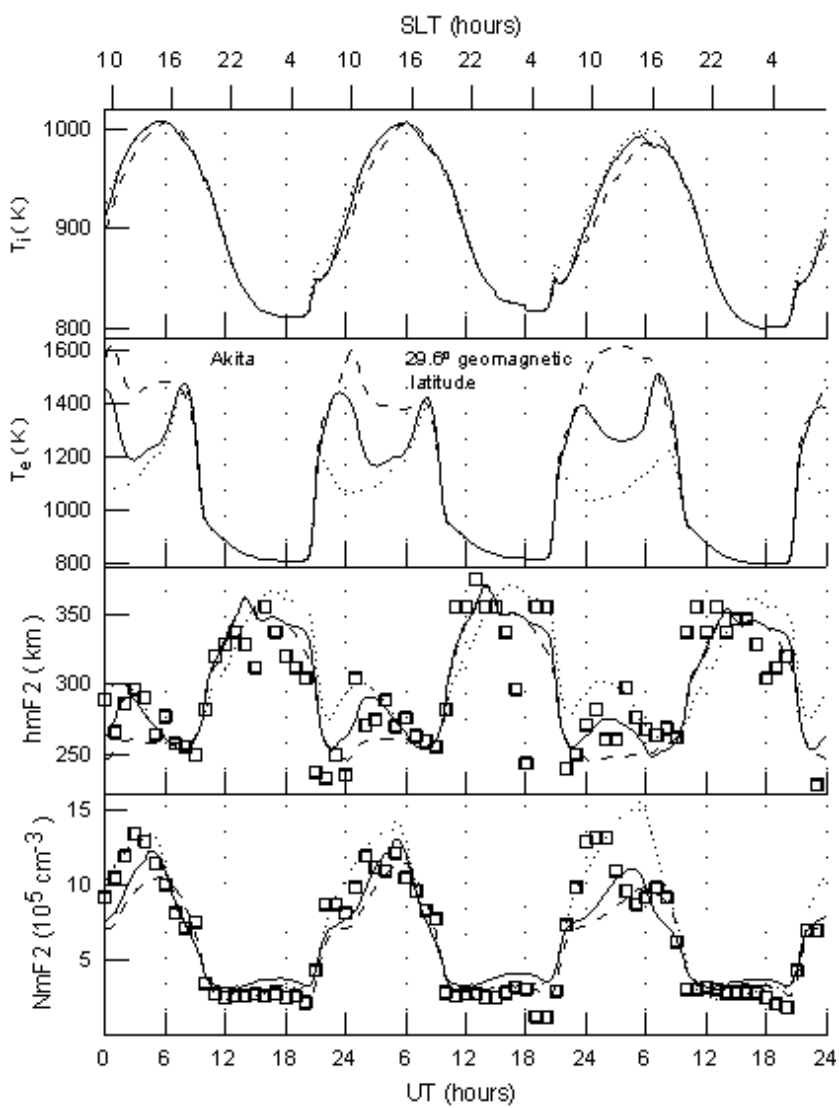

Fig. 9. From bottom to top, observed (squares) and calculated (lines) of $\mathrm{NmF} 2, \mathrm{hmF} 2$, electron temperatures and $\mathrm{O}^{+}$ion temperatures at the F2-region main peak altitude above the Akita ionosonde station during 19-21 March 1988. SLT is the local solar time at the Akita ionosonde station. The curves are the same as in Fig. 3.

while hmF2 of the crest electron density is less in the northern geomagnetic hemisphere than that in the southern geomagnetic hemisphere. It is clear that most of the asymmetry in $\mathrm{hmF} 2$ should come about through the asymmetry in the dynamical processes, which involve neutral winds and electric fields. As can be seen from the comparison between the solid and dashed lines of Fig. 13, the asymmetry in hmF2 and $\mathrm{NmF} 2$ is sharply decreased if the model uses the zero neutral wind. We conclude that the neutral wind given by the HWW90 model of Hedin et al. (1991) is asymmetric about the geomagnetic equator, and this asymmetry determines most of the asymmetry in $\mathrm{hmF} 2$ and $\mathrm{NmF} 2$ between the northern and southern geomagnetic hemispheres. This conclusion is in agreement with the previous results of Balan and Bailey (1995), Su et al. (1996), and Balan et al. (1997a, b). Dashed lines of Fig. 13 show that there is a small asymmetry in $\mathrm{hmF} 2$ and $\mathrm{NmF} 2$ between the northern and southern geomagnetic hemispheres for the zero neutral wind. This small asymmetry is caused by an asymmetry in the neutral temperature and densities between the northern and southern geomagnetic hemispheres. 


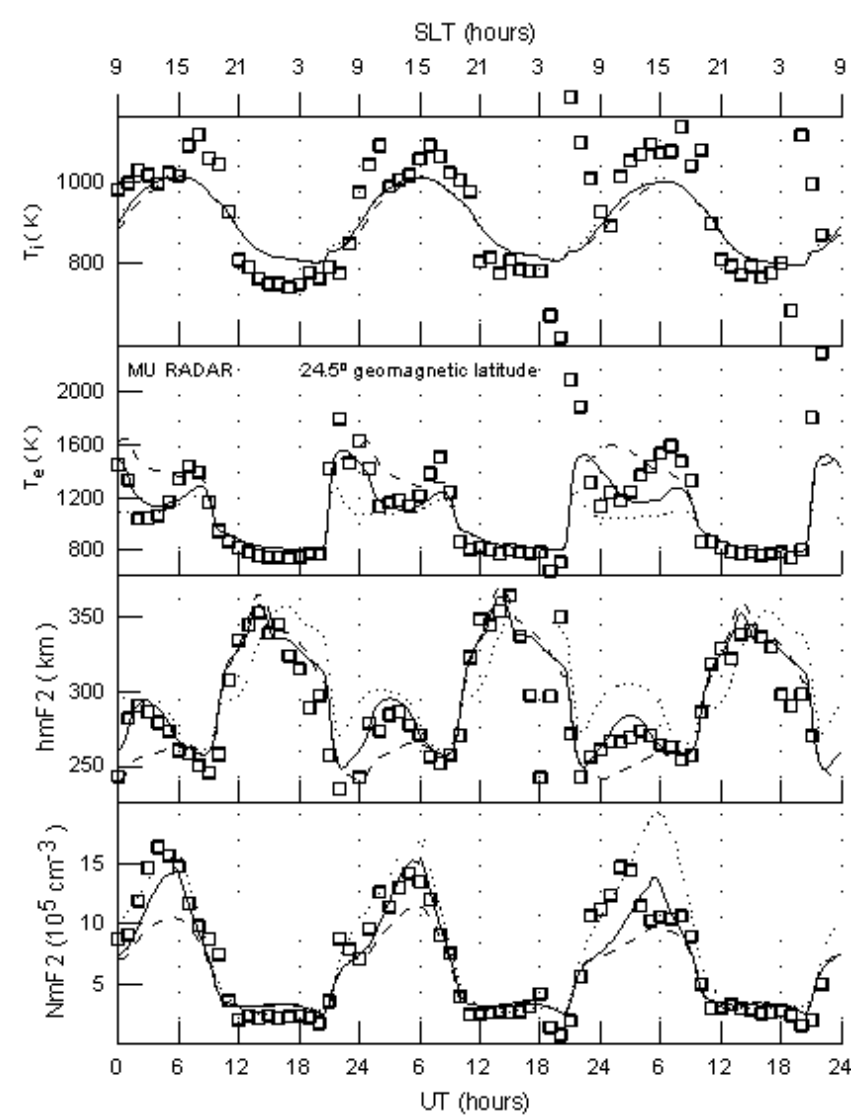

Fig. 10. Observed (squares) and calculated (lines) $\mathrm{NmF} 2$ and $\mathrm{hmF} 2$ (two lower panels), and electron and $\mathrm{O}^{+}$ion temperatures (two upper panels) at the F2-region main peak altitude above the MU radar during 19-21 March 1988. SLT is the solar local time at the MU radar. The curves are the same as in Fig. 3.

To obtain a better understanding of the relative role of the $\boldsymbol{E} \times \boldsymbol{B}$ drift at low-latitudes, calculations have been carried out from the model when the value of $\mathrm{E}_{\Lambda}$, used in producing results shown by the solid lines, was divided by a factor of 10 at all the studied geomagnetic latitudes and when the corrections of the NRLMSISE-00 [O] and meridional neutral HWW90 wind are the same as for solid lines. The model results are shown by dashed lines in Figs. 3-11.

During most of the daytime period the $\boldsymbol{E} \times \boldsymbol{B}$ drift lifts the plasma from lower field lines to higher field lines, while during most of the night-time period this drift moves ions and electrons from higher field lines to lower field lines. Simultaneously, the plasma diffuses along the magnetic field lines. The comparison between the solid and dashed lines in the bottom panel of Fig. 5 shows that, close to the geomagnetic equator, the $\mathrm{NmF} 2$ enhancement caused by the decrease in the plasma outflow is stronger than the reduction in $\mathrm{NmF} 2$ caused by the increase in the loss rate of $\mathrm{O}^{+}\left({ }^{4} \mathrm{~S}\right)$ ions. Therefore, the weakening of $\mathrm{E}_{\Lambda}$ leads to the $\mathrm{NmF} 2$ increase by day over the Manila sounder. The night-time $\mathrm{NmF} 2$ increase is a result of the daytime $\mathrm{NmF} 2$ increase and the decrease in the loss rate of $\mathrm{O}^{+}\left({ }^{4} \mathrm{~S}\right)$ ions due to the $\mathrm{hmF} 2$ increase caused by the weakening of $E_{\Lambda}$ over the Manila sounder. The complex interplay of the physical processes described above for the

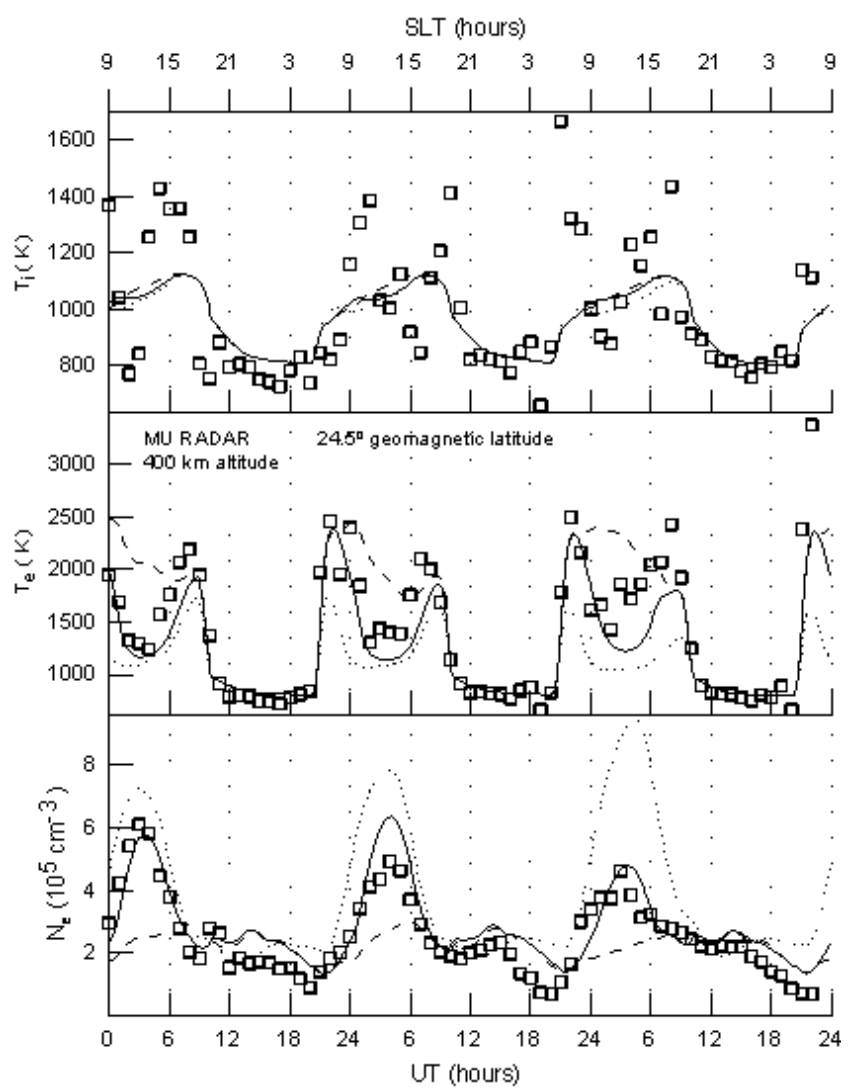

Fig. 11. The measured (squares) and calculated (lines) electron density (bottom panel) and electron (middle panel) and $\mathrm{O}^{+}$ion (top panel) temperatures at the $400 \mathrm{~km}$ altitude above the MU radar. The curves are the same as in Fig. 3.

Manila sounder determines the variations in $\mathrm{NmF} 2$ and $\mathrm{hmF} 2$ caused by the weakening of $\mathrm{E}_{\Lambda}$ over the other sounders (see Figs. 3-9).

The comparison between the solid and dashed lines in Figs. 10 and 11 shows that the $\boldsymbol{E} \times \boldsymbol{B}$ drift gives rise to considerable variations in $\mathrm{NmF} 2$ and $\mathrm{hmF} 2$, and in $\mathrm{N}_{e}$ at $400 \mathrm{~km}$ over the MU radar, and the magnitude of these daytime electron density variations is less at $\mathrm{hmF} 2$ in comparison with that at $400 \mathrm{~km}$. The weakening of $E_{\Lambda}$ by a factor of 10 changes the simulated daytime $\mathrm{NmF} 2$ by a factor of $0.9-1.4$, and the changes in $\mathrm{hmF} 2$ due to this weakening of $\mathrm{E}_{\Lambda}$ are between $-3 \mathrm{~km}$ and $34 \mathrm{~km}$, while the maximum daytime change in $\mathrm{N}_{e}$ is a factor of $0.85-2.3$ at $400 \mathrm{~km}$. The change in the night-time $\mathrm{N}_{e}$ is less than that by day. The weakening of $\mathrm{E}_{\Lambda}$ by a factor of 10 produces the change in the calculated nighttime $\mathrm{NmF} 2$ by a factor of $0.80-1.05$ and the changes in $\mathrm{hmF} 2$ are between $-10 \mathrm{~km}$ and $11 \mathrm{~km}$ by night, while the night-time change in $\mathrm{N}_{e}$ is a factor of $0.86-1.05$ at $400 \mathrm{~km}$. It should be noted that the studied changes in $\mathrm{N}_{e}$ are less pronounced at higher altitudes in the topside ionosphere and plasmasphere above the MU radar. For example, the maximum electron density change caused by the weakening of $E_{\Lambda}$ by a factor of 10 is $19 \%$ and $2 \%$ at $1000 \mathrm{~km}$ above the MU radar by day and by night, respectively. 


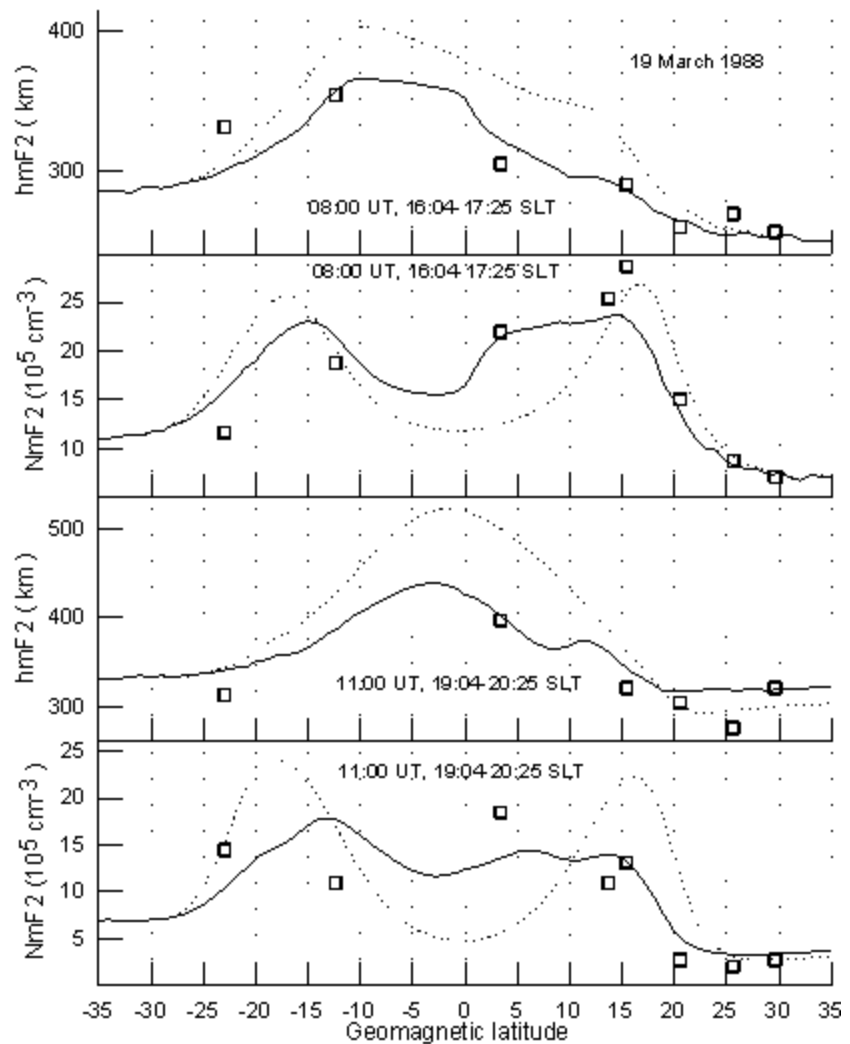

Fig. 12. Observed (squares) and calculated (lines) hmF2 and NmF2 at 08:00 UT (two upper panels) and 11:00 UT (two lower panels) on 19 March 1988. The measured hmF2 and NmF2 are taken from the ionospheric sounder station listed in Table 1. The curves are the same as in Fig. 3.

The model results presented in the bottom panels of Figs. 3-10 show that the magnitude of the electron density change caused by the weakening of $\mathrm{E}_{\Lambda}$ by a factor of 10 is decreased if the absolute value of the geomagnetic latitude is increased. As an example, above the Akita ionosonde station, this weakening in $\mathrm{E}_{\Lambda}$ changes the simulated daytime $\mathrm{NmF} 2$ by a factor of $0.91-1.34$ and hmF2 by the maximum value of $31 \mathrm{~km}$, while the maximum daytime electron density change is a factor of $0.90-1.96$ at $400 \mathrm{~km}$. We conclude that the use of the middle-latitude time dependent model of the ionosphere and plasmasphere, which does not take into account the $\boldsymbol{E} \times \boldsymbol{B}$ plasma drift, leads to noticeable errors in the calculated daytime electron density of the $\mathrm{F} 2$ region and a part of the topside ionosphere, even at geomagnetic latitudes of about $25^{\circ}-30^{\circ}$.

It is found by Pavlov (2003) that the daytime magnitude of $\mathrm{NmF} 2$ should be reduced up to a maximum factor of 1.44 between $-30^{\circ}$ and $+30^{\circ}$ of the geomagnetic latitude, due to enhanced vibrational excitation of $\mathrm{N}_{2}$ and $\mathrm{O}_{2}$ at high solar activity during the geomagnetically quiet period of 7 October 1957. We found that in the plane of the geomagnetic meridian at the geomagnetic longitude of $201^{\circ}$ the increase in the loss rate of $\mathrm{O}^{+}\left({ }^{4} \mathrm{~S}\right)$ ions, due to the vibrational excited $\mathrm{N}_{2}$ and $\mathrm{O}_{2}$, leads to the maximum decrease in the calculated $\mathrm{NmF} 2$ by a factor of 1.16 and to the maximum increase in

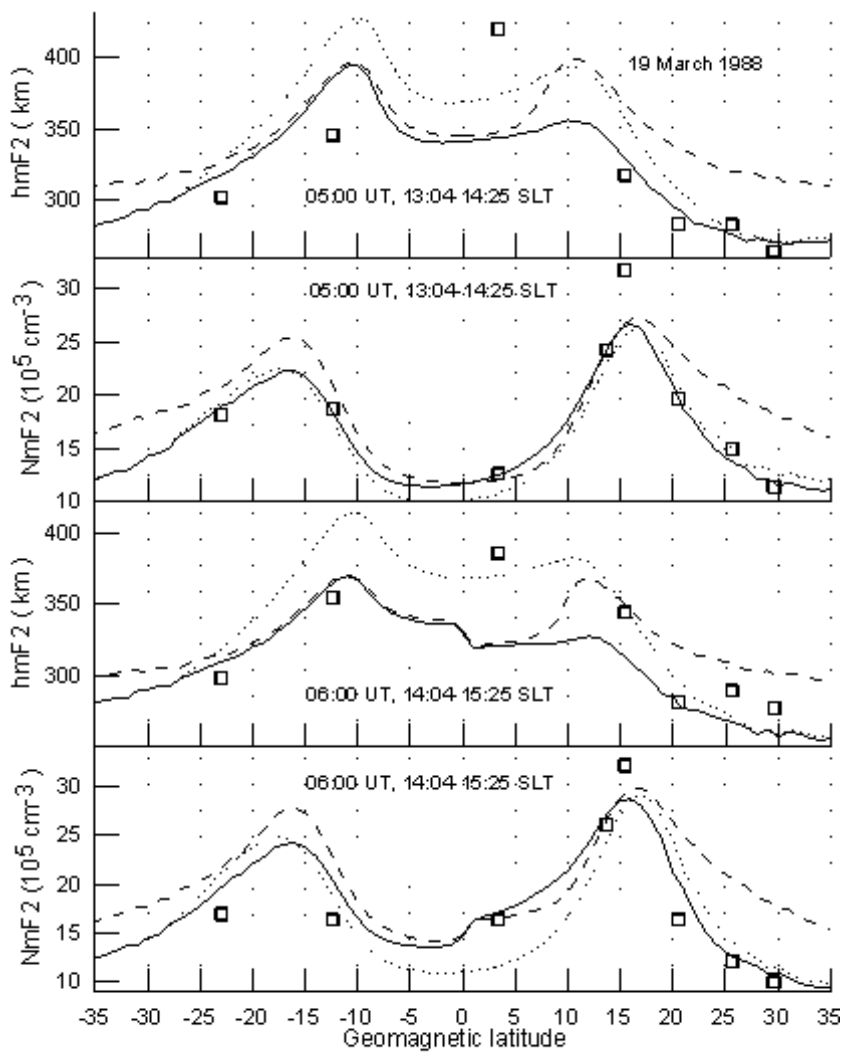

Fig. 13. Observed (squares) and calculated (lines) hmF2 and $\mathrm{NmF} 2$ at 08:00 UT (two upper panels) and 11:00 UT (two lower panels) on 19 March 1988. The measured $\mathrm{hmF} 2$ and $\mathrm{NmF} 2$ are taken from the ionospheric sounder station listed in Table 1. The solid and dotted curves are the same as in Fig. 3. Dashed lines show the results produced by the model with the corrected equatorial $\mathrm{E}_{\Lambda}$ given by the solid line in Fig. 1, zero neutral wind, and the NRLMSISE-00 neutral temperature and densities with the same correction of [O] as for the solid lines.

the calculated $\mathrm{hmF} 2$ of $5 \mathrm{~km}$ in the ionosphere between $-30^{\circ}$ and $+30^{\circ}$ of the geomagnetic latitude at moderate solar activity. We conclude that the effect of vibrationally excited $\mathrm{N}_{2}$ and $\mathrm{O}_{2}$ on $\mathrm{N}_{e}$ of the low-latitude ionosphere is decreased by decreasing the solar activity level.

The measured hmF2 presented in Figs. 3-9 show large fluctuations. The possible source of this scatter in hmF2 is the dependence of $\mathrm{hmF} 2$ on $\mathrm{M}(3000) \mathrm{F} 2$ and $\Delta \mathrm{M}$ given by Dudeney (1983), which determines hmF2 diurnal variations with errors. The ionosondes listed in Table 1 are not located at the geomagnetic longitudes of $201^{\circ}$, which is used in the model calculations. This geomagnetic longitude displacement can explain a part of the disagreement between the modeled and measured hmF2 and NmF2 in Figs. 3-13. A part of these discrepancies is probably due to the uncertainties in the model inputs, such as the possible inability of the NRLMSIS-00 model to accurately predict the densities and temperature for the studied period at low-latitudes, and uncertainties in the neutral wind, EUV fluxes, chemical rate coefficients, photoionization, photoabsorption and electron impact cross sections for $\mathrm{N}_{2}, \mathrm{O}_{2}$, and $\mathrm{O}$. 


\subsection{Electron and ion temperature variations}

The two upper panels of Figs. 3-10 show the calculated (lines) and measured (squares) electron, $\mathrm{T}_{e}$, and ion, $\mathrm{T}_{i}$, temperatures at the F2-region main peak altitude for the 19-21 March 1988 time period above the Darwin (Fig. 3), Vanimo (Fig. 4), Manila (Fig. 5), Chung-Li (Fig. 6), Okinawa (Fig. 7), Yamagawa (Fig. 8), and Akita (Figu. 9) ionosonde stations and above the MU radar (Fig. 10). Figure 11 shows the measured (squares) and calculated (lines) electron (middle panel) and $\mathrm{O}^{+}$ion (top panel) temperatures at the $400 \mathrm{~km}$ altitude above the MU radar.

It is evident from comparison between solid and dotted lines in Figs. 3-10 that the corrections in the equatorial upward $\boldsymbol{E} \times \boldsymbol{B}$ drift, the model HWW90 wind, and the NRLMSISE-00 [O] produce negligible effects in $\mathrm{T}_{i}$ during 19-21 March 1988, while there are some electron temperature variations due to these input model parameter changes after sunrise. The duration of the time period, where this difference in the calculated electron temperatures is noticeable, is increased by increasing the absolute value of the geomagnetic latitude.

Figures 3-11 show that the diurnal variations of $\mathrm{T}_{e}$ are characterized by morning and evening peaks above the Darwin, Yamagawa, Kokubunji, and Akita ionosonde stations and over the MU radar, while the model produces only morning peaks and a broad daytime maximum in $\mathrm{T}_{e}$ above the Vanimo, Manila, Chung-Li, and Okinawa ionosonde stations. The calculated evening $\mathrm{T}_{e}$ peaks are less than those measured by the MU radar. If we take into account the accuracy of the MU radar $\mathrm{T}_{e}$ and $\mathrm{T}_{i}$ measurements (Sato et al., 1989) and uncertainties of model calculations (see Sect. 4.2), then we conclude that $\mathrm{T}_{e}$ and $\mathrm{T}_{i}$ observed by the MU radar are in reasonable agreement with the model results shown by the solid lines in the two upper panels of Figs. 1011 , although there are some quantitative differences. The reasonable agreement between the measured $\mathrm{T}_{e}$ and $\mathrm{T}_{i}$ and the modeled $\mathrm{T}_{e}$ and $\mathrm{T}_{i}$ determines the reliability of the calculated $\mathrm{T}_{e}$ and $\mathrm{T}_{i}$ at other geomagnetic latitudes.

The relative magnitudes of the cooling rates are of particular interest for understanding the main processes, which determine the electron temperature. We found that the main cooling rates of thermal electrons in the low- and middlelatitude ionosphere are electron-ion Coulomb collisions, vibrational excitation of $\mathrm{N}_{2}$ and $\mathrm{O}_{2}$ and rotational excitation of $\mathrm{N}_{2}$.

The electron-ion cooling rate of thermal electrons, which is the predominant cooling rate at $\mathrm{hmF} 2$ and the main cooling rate in the plasmasphere and topside ionosphere, is proportional to $\mathrm{N}_{e}$ squared. As a result, variations in $\mathrm{N}_{e}$ cause variations in $\mathrm{T}_{e}$. It follows from the profiles of $\mathrm{T}_{e}$ and $\mathrm{T}_{i}$ measured at Jicamarca that the enlargement of the altitude region with $\mathrm{T}_{e}>\mathrm{T}_{i}$ occurs at sunrise at all heights to at least $600 \mathrm{~km}$ (McClure, 1969). Our calculations show that at sunrise, there is a rapid heating of the ambient electrons by photoelectrons, and the difference between the electron and neutral temperature could be increased because nighttime electron densities are less than those by day, and the electron cooling during morning conditions is less than that by day. This expands the altitude region at which $\mathrm{T}_{e}>\mathrm{T}_{i}$ near the equator and leads to the sunrise electron temperature peaks at $\mathrm{hmF} 2$ altitudes above the ionosonde stations. After the abrupt increase at sunrise, the electron temperature decreases, owing to the increasing electron density due to the increase in the cooling rate of thermal electrons. An appearance, a magnitude, and a disappearance of a morning electron temperature peak at hmF2 depend on a minimum value of the night-time NmF2 before sunrise, because the morning NmF2 is a function of this minimum night-time NmF2.

Like the middle-latitude F-region ionosphere, the nocturnal low-latitude F-region is maintained due to the lowlatitude daytime F-region decay and by a downward flow of ionization from the plasmasphere. The role of a downward flow of ionization from the plasmasphere is increased before sunrise. A plasma tube length and total plasma tube content are decreased with lowering the geomagnetic latitude. It means that an increase in the absolute value of the geomagnetic latitude could lead to an increase in a downward flow of ionization from the plasmasphere, the increase in the night-time electron density before sunrise and the resulting decrease in the magnitude of the morning electron temperature peak.

The downward night-time and morning $\boldsymbol{E} \times \boldsymbol{B}$ drift resulting from $\mathrm{E}_{\Lambda}<0$ moves the ionospheric and plasmaspheric electrons and ions from middle to low geomagnetic latitudes, and ions and electrons then diffuse downward along magnetic field lines (the solid line in Fig. 1 shows that the requirement of $\mathrm{E}_{\Lambda}<0$ is correct over the geomagnetic equator from 20:06 SLT to 24:00 SLT and from 24:00 SLT to 06:15 SLT, where SLT is the local solar time at the geomagnetic equator and $201^{\circ}$ geomagnetic longitude). The resulting effect of these physical processes on $\mathrm{NmF} 2$ depends on the competition between an enhancement in $\mathrm{N}_{e}$ caused by a plasma inflow and an decrease in $\mathrm{N}_{e}$ caused by an increase in the loss rate of $\mathrm{O}^{+}\left({ }^{4} \mathrm{~S}\right)$ ions due to a $\mathrm{NmF} 2$ peak layer lowering.

Figure 14 shows the calculated minimum night-time F2 layer peak electron density, $\mathrm{NmF}_{2}$ min, (panel (a)) and its F2 peak altitude, $\mathrm{hmF} 2_{\min }$, (panel (b)), the dependence of the calculated morning electron temperature peak, $\mathrm{T}_{e}^{\text {peak }}$, on the geomagnetic latitude (panel (d)), and $\mathrm{NmF} 2_{\text {peak }}$ (panel (c)), which is the value of NmF2 at the point of the morning electron temperature peak calculation. The results shown by the solid lines in Fig. 14 were calculated by the model with the corrected equatorial $\mathrm{E}_{\Lambda}$ given by the solid line in Fig. 1, the corrected HWW90 wind, and the NRLMSISE-00 model with the corrected value of [O]. Dashed lines in Fig. 14 show the results given by the model with the same corrections of the NRLMSISE-00 [O] and meridional neutral HWW90 wind as for solid lines, but when the value of the corrected $E_{\Lambda}$, used in producing results shown by the solid lines, was divided by a factor of 10 at all the studied geomagnetic latitudes, only for the time periods when the equatorial value of $\mathrm{E}_{\Lambda}$, given by the solid line in Fig. 1, is negative (i.e. when the 
equatorial $\boldsymbol{E} \times \boldsymbol{B}$ plasma drift is downward). Dotted lines in Fig. 14 show the results produced by the model with the corrected equatorial $\mathrm{E}_{\Lambda}$ given by the solid line in Fig. 1, zero neutral wind, and the NRLMSISE-00 model with the same correction of $[\mathrm{O}]$ as for the solid lines.

By comparing the solid lines in the panels (a) and (c) of Fig. 14, it is seen that the geomagnetic latitude variation of $\mathrm{NmF} 2_{\text {peak }}$ is similar to the dependence of $\mathrm{NmF}_{2}$ min on the geomagnetic latitude. As a result, the model calculations of this work provide evidence that an appearance, a magnitude, and a disappearance of a morning electron temperature peak at hmF2 depend on physical processes which determine $\mathrm{NmF} 2_{\text {min }}$.

It follows from the comparison between the corresponding solid and dashed lines in Fig. 14 that the decrease in the equatorial night-time downward $\boldsymbol{E} \times \boldsymbol{B}$ drift by a factor of 10 leads to the increase in NmF2 between about $-28^{\circ}$ and $28^{\circ}$ geomagnetic latitudes, i.e. the $\mathrm{NmF} 2$ reduction caused by the increase in the loss rate of $\mathrm{O}^{+}\left({ }^{4} \mathrm{~S}\right)$ ions is stronger than the enhancement in $\mathrm{NmF} 2$ caused by the plasma inflow. The dashed lines in Fig. 14 show that the equatorial anomaly caused by the upward $\boldsymbol{E} \times \boldsymbol{B}$ drift by day is maintained in the night-time low-latitude ionosphere due to the low-latitude daytime F-region decay, and a downward flow of ionization from the plasmasphere is not important. It follows from Fig. 14 that the night-time and morning downward $\boldsymbol{E} \times \boldsymbol{B}$ drift causes the decrease of $\mathrm{NmF} 2$ and the resulting increase of the morning peak in $\mathrm{T}_{e}$. The night-time and morning downward $\boldsymbol{E} \times \boldsymbol{B}$ drift becomes more effective in lowering $\mathrm{N}_{e}$ with lowering the geomagnetic latitude., i.e. a decrease in the absolute value of the geomagnetic latitude leads to the decrease in $\mathrm{N}_{e}$ close to sunrise, resulting in an increase in the magnitude of the morning $\mathrm{T}_{e}$ peak. It follows from panel (d) of Fig. 14 that the role of the night-time and morning downward $\boldsymbol{E} \times \boldsymbol{B}$ drift in creating the morning $\mathrm{T}_{e}$ peak is negligible above about $27^{\circ}$ and below about $-27^{\circ}$ geomagnetic latitude.

To obtain a better understanding of the relative role of the plasma drift caused by the neutral wind in the formation of the morning $\mathrm{T}_{e}$ peak, calculations have been carried out from the model when the values of the components of the neutral wind, used in producing results shown by the solid lines, were taken to be zero and when the corrections in $\mathrm{E}_{\Lambda}$ and the NRLMSISE-00 [O] are the same as for solid lines. We compare the results of these model calculations (which are not shown in Figs. 3-10) with those shown by the solid lines in Figs. 3-10. We found that, above each ionosonde station of Table 1 and above the MU radar the magnitude of the morning $\mathrm{T}_{e}$ peak produced by the model without the neutral wind is increased by about $50-960 \mathrm{~K}$ and the width of the peak is decreased in comparison with the morning peak shown by the solid lines in Figs. 3-10.

By comparing the solid and dotted lines in the bottom panel of Fig. 14, it is seen that a wind, which is equatorward by night in equinox at moderate solar activity, forces the F2 layer to lift upward to high altitudes of weak chemical $\mathrm{O}^{+}\left({ }^{4} \mathrm{~S}\right)$ ion losses, increasing the electron density to high

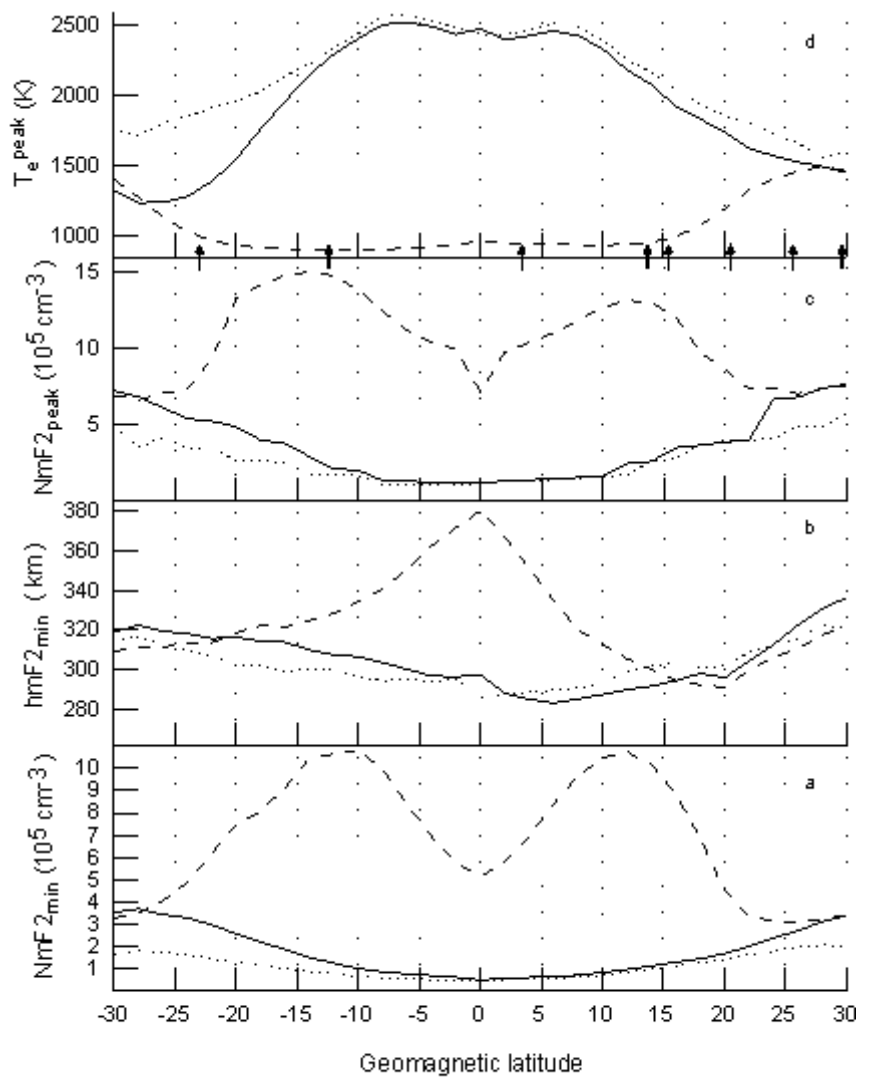

Fig. 14. The calculated minimum night-time $F 2$ layer peak electron density, $\mathrm{NmF} 2_{\text {min }}$, (panel (a)) and its $\mathrm{F} 2$ peak altitude, $\mathrm{hmF} 2_{\text {min }}$ (panel (b)). The dependences of the calculated morning electron temperature peak, $\mathrm{T}_{e}^{\text {peak }}$, on the geomagnetic latitude is presented in the panel (d). The panel (c) shows the calculated $N m F 2_{\text {peak }}$, which is $\mathrm{NmF} 2$ at the point of the morning electron temperature peak calculation. Solid lines show the results given by the model with the corrected equatorial $\mathrm{E}_{\Lambda}$, given by the solid line in Fig. 1, the corrected HWW90 wind, and the NRLMSISE-00 model with the corrected value of $[\mathrm{O}]$. Dotted lines show the results produced by the model with the corrected equatorial $\mathrm{E}_{\Lambda}$ given by the solid line in Fig. 1, zero neutral wind, and the NRLMSISE-00 model with the same correction of $[\mathrm{O}]$ as for the solid lines. The results shown by dashed lines were calculated by the model with the same corrections of the NRLMSISE-00 [O] and meridional neutral HWW90 wind as for the solid lines, but only when the value of the corrected $E_{\Lambda}$, used in producing the results shown by the solid lines, divided by a factor of 10 at all the studied geomagnetic latitudes, only for the time periods when the equatorial value of $\mathrm{E}_{\Lambda}$, given by the solid line in Fig. 1, is negative (i.e. when the equatorial $\boldsymbol{E} \times \boldsymbol{B}$ plasma drift is downward). The solid, dotted and dashed lines in panels (a, b) correspond to 04:41-05:29 SLT on 20 March, 05:09-05:28 SLT on 20 March, and 05:11-05:31 SLT on 20 March, respectively. The solid, dotted and dashed lines in panels (c, d) correspond to 05:4808:21 SLT on 20 March, 05:48-06:31 SLT on 20 March, and 06:3308:55 SLT on 20 March, respectively. Arrows at the top mark the locations of the Darwin, Vanimo, Manila, Chung-Li, Okinawa, Yamagawa, Kokubunji, and Akita sounders at $-23.0^{\circ},-12.4^{\circ}, 3.4^{\circ}$, $13.7^{\circ}, 15.4^{\circ}, 29.6^{\circ}, 20.5^{\circ}, 25.6^{\circ}$, and $29.6^{\circ}$ geomagnetic latitudes, respectively. 


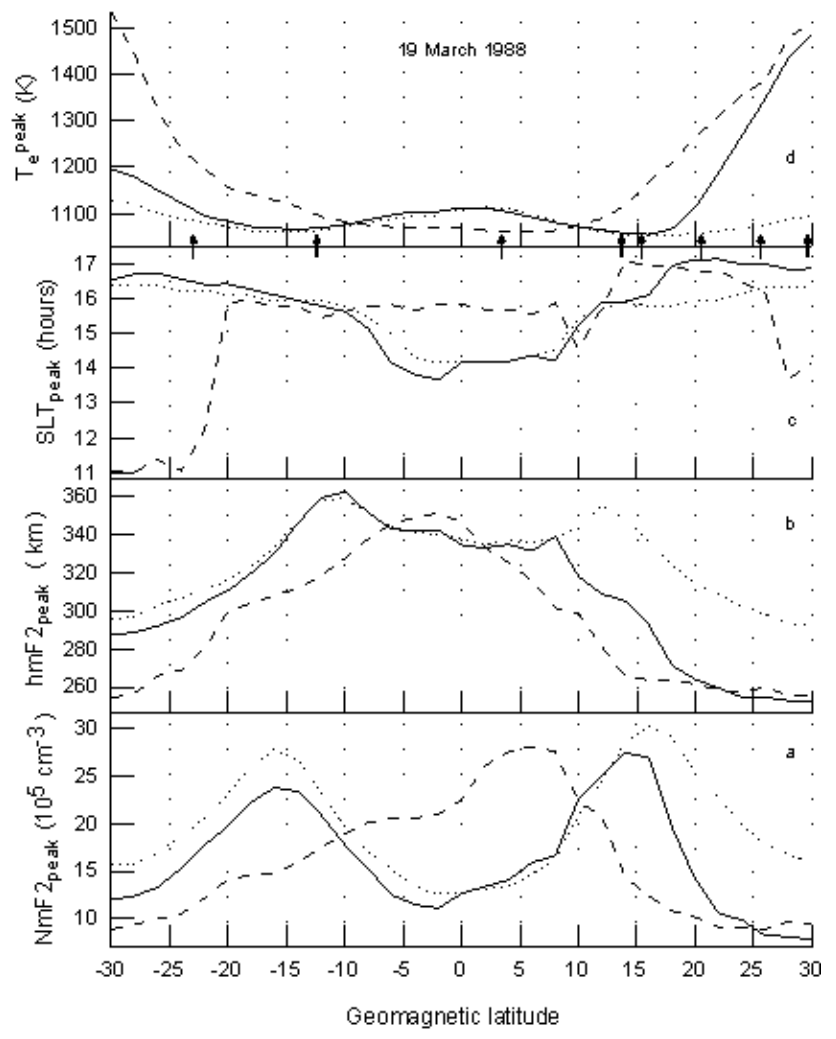

Fig. 15. The latitude dependence of the daytime and evening electron temperature peaks (panel (d)), $\mathrm{T}_{e}^{\text {peak }}$, the time, $\mathrm{SLT}_{\text {peak }}$, of the electron temperature peak appearance (panel (c)), the value of the F2 peak layer density, $\mathrm{NmF}_{\text {peak }}$, at $\mathrm{SLT}_{\text {peak }}$ (panel (a)), and the F2 peak layer altitude, $\mathrm{hmF} 2_{\text {peak }}$ (panel (b)) at $\mathrm{SLT}_{\text {peak }}$ on 19 March 1988. The electron temperature peak is taken to be closest to sunset. The results shown by the solid lines were calculated by the model with the corrected zonal electric field, given by the solid line in Fig. 1, the corrected HWW90 wind, and the NRLMSISE00 model with the corrected value of [O]. The dotted lines show the results produced by the model with the same zonal electric field as for the solid lines, zero neutral wind, and the NRLMSISE-00 model with the same correction of [O] as for the solid lines. The results shown by the dashed lines were calculated by the model with the same corrections of the NRLMSISE-00 [O] and meridional neutral HWW90 wind as for the solid lines, but only when the value of the corrected zonal electric field, used in producing results shown by the solid lines, was divided by a factor of 10 at all the studied geomagnetic latitudes. Arrows at the top mark the locations of the Darwin, Vanimo, Manila, Chung-Li, Okinawa, Yamagawa, Kokubunji, and Akita sounders at $-23.0^{\circ},-12.4^{\circ}, 3.4^{\circ}, 13.7^{\circ}, 15.4^{\circ}, 29.6^{\circ}, 20.5^{\circ}$, $25.6^{\circ}$, and $29.6^{\circ}$ geomagnetic latitudes, respectively.

values before sunrise. The increase in the absolute value of the geomagnetic latitude leads to the strengthening of the effect of the plasma drift due to the neutral wind on the electron density, the increase in the night-time electron density before sunrise and the resulting decrease in the magnitude of the morning electron temperature peak. As it is seen from the comparison between the corresponding solid and dotted lines in the top panel of Fig. 14, the effect of the plasma drift caused by the night-time neutral wind is to reduce the morning $\mathrm{T}_{e}$ peak through the increase in $\mathrm{N}_{e}$ at all geomagnetic latitudes and the effect of this plasma drift on the formation of the morning $\mathrm{T}_{e}$ peak is decreased by decreasing the absolute value of the geomagnetic latitude. It should be noted that a wind, which is poleward in the morning time periods decreases hmF2, causing an increase in the loss rate of $\mathrm{O}^{+}\left({ }^{4} \mathrm{~S}\right)$ ions at $\mathrm{hmF} 2$, a decrease in $\mathrm{NmF} 2$ and helps to create an increase in $\mathrm{T}_{e}$, in agreement with the conclusions of Otsuka et al. (1998).

Figure 15 shows the latitude dependence of the daytime and evening electron temperature peaks (panel (d)), $\mathrm{T}_{e}^{\text {peak }}$, the time, SLT $_{\text {peak }}$, of the electron temperature peak appearance (panel (c)), the value of the F2 peak layer density, $\mathrm{NmF} 2_{\text {peak }}$, at $\mathrm{SLT}_{\text {peak }}$ (panel (a)), and the F2 peak layer altitude, hmF2 $2_{\text {peak }}$, at SLT $_{\text {peak }}$ (panel (b)) on 19 March 1988. The electron temperature peak is taken to be closest to sunset. The results shown by the solid lines were calculated by the model with the corrected zonal electric field given by the solid line in Fig. 1, the corrected HWW90 wind, and the NRLMSISE-00 neutral temperature and densities with the corrected value of $[\mathrm{O}]$. The dotted lines show the results produced by the model with the same $\mathrm{E}_{\Lambda}$ as for the solid lines, zero neutral wind, and the NRLMSISE-00 neutral temperature and densities with the same correction of [O] as for the solid lines. The results shown by the dashed lines were calculated by the model with the same corrections of the NRLMSISE-00 [O] and meridional neutral HWW90 wind as for the solid lines, but only when the value of $E_{\Lambda}$, used in producing results shown by the solid lines, was divided by a factor of 10 at all the studied geomagnetic latitudes.

The present study has shown that the magnitude of the evening $\mathrm{T}_{e}$ peak and its time location are decreased by lowering the geomagnetic latitude, and the evening $\mathrm{T}_{e}$ peak disappears from about $-10^{\circ}$ to about $10^{\circ}$ geomagnetic latitude on 19 March, and only the afternoon daytime $\mathrm{T}_{e}$ peaks exist in this latitude range if the corrected HWW90 wind (solid lines in Fig. 15) or zero wind (dashed lines in Fig. 15) are used in the calculations by the model with the corrected zonal electric field, given by crosses in Fig. 1, and the corrected NRLMSISE-00 atomic oxygen density.

It follows from the comparison between the solid and dotted lines in the panel (d) of Fig. 15 that the use of zero wind instead of the corrected HWW90 wind leads to a decrease in the magnitude of the evening electron temperature peak. The plasma drift along magnetic field lines due to the neutral wind can increase or decrease $\mathrm{hmF}$, leading to the decrease or increase in the loss rate of $\mathrm{O}^{+}\left({ }^{4} \mathrm{~S}\right)$ ions at $\mathrm{hmF} 2$, causing an increase or a decrease in $\mathrm{NmF} 2$ and, as a result, leading to the disappearance or appearance of the evening peak in $\mathrm{T}_{e}$, respectively.

A decrease in the production rate of $\mathrm{O}^{+}$ions by solar radiation caused by a solar zenith angle increase results in a $\mathrm{NmF} 2$ decrease with time during an evening time period, and a feebly marked evening peak in $\mathrm{T}_{e}$ is created by this evening decrease in $\mathrm{N}_{e}$. It follows from the model calculations that a 
wind, which is poleward in equinox by day at moderate solar activity, forces the $\mathrm{F} 2$ layer to descend to low altitudes of heavy chemical $\mathrm{O}^{+}\left({ }^{4} \mathrm{~S}\right)$ ion losses, reducing $\mathrm{N}_{e}$ to low values before sunset. Due to this poleward wind, the evening NmF2 decrease in time becomes strong, producing a strongly pronounced decrease in the thermal electron cooling rate and the resulting increase in the evening $\mathrm{T}_{e}$ peak, in agreement with the results of Otsuka et al. (1998). The decrease in the absolute value of the geomagnetic latitude leads to the weakening of the effect of the plasma drift due to the neutral wind on $\mathrm{N}_{e}$. This explains the calculated latitude variations in the strength of the evening peak in $\mathrm{T}_{e}$.

The values of $\mathrm{NmF} 2$ and $\mathrm{hmF} 2$ which determine the magnitudes of the peaks in $\mathrm{T}_{e}$ at $\mathrm{hmF} 2$ depend on the magnitude and the direction of the $\boldsymbol{E} \times \boldsymbol{B}$ drift. By comparing the solid and dashed lines in Fig. 15, it can be seen that the weakening of $E_{\Lambda}$ by a factor of 10 causes the decrease in the magnitude of the peak in $\mathrm{T}_{e}$ between about $-10^{\circ}$ and $10^{\circ}$ geomagnetic latitude, and this magnitude is increased from about $-10^{\circ}$ to $-30^{\circ}$ geomagnetic latitude and between about $10^{\circ}$ and $30^{\circ}$ geomagnetic latitude on 19 March. This weakening of $E_{\Lambda}$ leads to the disappearance of an evening electron temperature peak close to $-21^{\circ}$ geomagnetic latitude and, as a result, only a daytime peak in $\mathrm{T}_{e}$ exists on 19 March from about $21^{\circ}$ to $-30^{\circ}$ geomagnetic latitude (see the dashed line in the panel (c) of Fig. 15 and the dashed line in Fig. 3).

The comparison between the solid and dashed lines in Figs. 3-8 shows that the weakening of $E_{\Lambda}$ by a factor of 10 leads to the disappearance of the morning peak in $\mathrm{T}_{e}$ over the Manila sounder and to the decrease of the morning peak in $\mathrm{T}_{e}$ over the Yamagawa, Okinawa, Chung-Li, Manila, Vanimo, and Darwin sounders. It is also necessary to point out that the evening peak in $\mathrm{T}_{e}$ is slightly less pronounced over the Darwin and Yamagava ionosonde stations due to the weakening of $E_{\Lambda}$ by a factor of 10 (see Figs. 3 and 8). Figure 9 shows that this weakening of $\mathrm{E}_{\Lambda}$ leads to the disappearance of the evening $\mathrm{T}_{e}$ peak on 20-21 March 1988 over the Akita sounder due to a decrease in the daytime NmF2 and an increase in the evening $\mathrm{NmF} 2$.

A comparison of the solid and dashed lines in the two upper panels of Fig. 10 and in the middle and top panels of Fig. 11 shows the effect of the $\boldsymbol{E} \times \boldsymbol{B}$ drift on $\mathrm{T}_{e}$ and $\mathrm{T}_{i}$ at hmF2 (Fig. 10) and $400 \mathrm{~km}$ (Fig. 11) over the MU radar. It is seen that this very large decrease in the $\boldsymbol{E} \times \boldsymbol{B}$ drift can be important in changing the evening and morning $\mathrm{T}_{e}$ peaks by eliminating the minimum between these peaks. The daytime decrease in $\mathrm{N}_{e}$ caused by the weakening of $\mathrm{E}_{\Lambda}$ by a factor of 10 leads to an increase in the daytime $\mathrm{T}_{e}$ due to the decrease in the cooling rate of thermal electrons. The ion temperature depends on $\mathrm{T}_{e}$ and $\mathrm{N}_{e}$ and, therefore, this weakening of $\mathrm{E}_{\Lambda}$ changes $\mathrm{T}_{i}$. It should be noted that the increase in altitude causes the increase of the relative role of the electron heat flow along the magnetic field line in comparison with cooling of thermal electrons, and the change in $\mathrm{T}_{e}$ at $400 \mathrm{~km}$ is less than that at $\mathrm{hmF}$. As a result, over the MU radar, the daytime $\mathrm{N}_{e}$ decrease leads to the daytime maximum increases in $\mathrm{T}_{e}$ of $400 \mathrm{~K}$ at hmF2 and $1000 \mathrm{~K}$ at $400 \mathrm{~km}$, while the maxi- mum night-time decrease in $\mathrm{T}_{e}$ caused by the increase in $\mathrm{N}_{e}$ is close to $100 \mathrm{~K}$ at hmF2 and at $400 \mathrm{~km}$. The changes in the daytime and night-time $T_{i}$ caused by the weakening of $\mathrm{E}_{\Lambda}$ by a factor of 10 are less than $40 \mathrm{~K}$ at hmF2 and at $400 \mathrm{~km}$ over the MU radar. These model calculations provide evidence that the use of the middle-latitude time dependent model of the ionosphere and plasmasphere, which does not take into account the $\boldsymbol{E} \times \boldsymbol{B}$ plasma drift, leads to noticeable errors in the calculated daytime electron temperature of the F2 region and a part of the topside ionosphere, even at geomagnetic latitudes of about $25^{\circ}-30^{\circ}$.

\section{Conclusions}

We have presented a comparison between the modeled $\mathrm{NmF} 2$ and $\mathrm{hmF} 2$, and $\mathrm{NmF} 2$ and $\mathrm{hmF} 2$, which were observed by the Akita, Kokubunji, Yamagawa, Okinawa, Chung-Li, Manila, Vanimo, and Darwin ionospheric sounders and by the MU radar during 19-21 March 1988. A comparison between the calculated $\mathrm{T}_{e}$ and $\mathrm{T}_{i}$ and those measured by the MU radar is presented for 19-21 March 1988. The model reproduces major features of the data.

It is found that there is a large disagreement between the measured and modeled $\mathrm{hmF} 2$ from about 07:00 UT to about 11:00 UT if the equatorial upward $\boldsymbol{E} \times \boldsymbol{B}$ drift given by Scherliess and Fejer (1999) is used. The discovered modification of the equatorial upward $\boldsymbol{E} \times \boldsymbol{B}$ drift weakens the effect of the fountain in NmF2, bringing the modeled and measured $\mathrm{hmF} 2$ and $\mathrm{NmF} 2$ into reasonable agreement. In agreement with the ionosonde measurements of $\mathrm{NmF} 2$, the model produces the onset of the equatorial anomaly crest formation close to 02:00 UT, shows that the equatorial anomaly effect is most pronounced close to 06:00 UT, and produces the crest disappearance close to 15:00 UT. It has been found that the north-south asymmetries in the observed $\mathrm{NmF} 2$ and hmF2 about the geomagnetic equator are mainly caused by the asymmetry in the neutral wind about the geomagnetic equator due to the displacement of the geographic and magnetic equators and the magnetic declination angle.

It is shown that the dependence of $\mathrm{NmF} 2$ on $\left[\mathrm{N}_{2}\right]$ and $\left[\mathrm{O}_{2}\right]$ is weaker than the dependence of $\mathrm{NmF} 2$ on [O] by day close to the geomagnetic equator. We conclude that $\mathrm{NmF} 2$ is not proportional to $[\mathrm{O}] /\left[\mathrm{N}_{2}\right]$ or to $[\mathrm{O}] /\left[\mathrm{O}_{2}\right]$ in the daytime ionosphere close to the geomagnetic equator. It is shown that the increase in the loss rate of $\mathrm{O}^{+}\left({ }^{4} \mathrm{~S}\right)$ ions, due to the vibrational excited $\mathrm{N}_{2}$ and $\mathrm{O}_{2}$, leads to the decrease in the calculated $\mathrm{NmF} 2$, up to a maximum factor of 1.16 and to the increase in the calculated $\mathrm{hmF} 2$, up to a maximum value of $5 \mathrm{~km}$ between $-30^{\circ}$ and $+30^{\circ}$ geomagnetic latitude at moderate solar activity.

The diurnal variations of $\mathrm{T}_{e}$ are characterized by morning and evening peaks above the Yamagawa, Kokubunji, and Akita ionosonde stations and over the MU radar, while there is only a morning peak in $\mathrm{T}_{e}$ above the Darwin, Vanimo, Manila, Chung-Li, and Okinawa ionosonde stations. There is a rapid heating of daytime electrons by photoelectrons, and 
the difference between $\mathrm{T}_{e}$ and $\mathrm{T}_{i}$ is increased after sunrise because nighttime $\mathrm{N}_{e}$ are less than those by day, and the resulting electron cooling is less than that by day. After the abrupt morning increase, $T_{e}$ decreases due to the increase in the cooling rate of thermal electrons caused by the increase in $\mathrm{N}_{e}$. The night-time and morning $\boldsymbol{E} \times \boldsymbol{B}$ drift moves the plasma from middle to low geomagnetic latitudes, and the plasma then diffuses downward along $\boldsymbol{B}$. We found that the $\mathrm{NmF} 2$ reduction caused by the increase in the loss rate of $\mathrm{O}^{+}\left({ }^{4} \mathrm{~S}\right)$ ions is stronger than the enhancement in $\mathrm{NmF} 2$ caused by the plasma inflow. We conclude that the night-time and morning downward $\boldsymbol{E} \times \boldsymbol{B}$ drift causes the decrease in NmF2 close to sunrise, resulting in an increase in the morning $\mathrm{T}_{e}$ peak. The night-time and morning downward $\boldsymbol{E} \times \boldsymbol{B}$ drift becomes more effective in lowering $\mathrm{N}_{e}$ by lowering the geomagnetic latitude, i.e. the geomagnetic latitude lowering leads to a decrease in the night-time and morning $\mathrm{N}_{e}$ resulting in an increase in the morning $\mathrm{T}_{e}$ peak. The effect of the plasma drift caused by the night-time neutral wind is to reduce the morning $\mathrm{T}_{e}$ peak through the increase in $\mathrm{N}_{e}$, and this effect is decreased by decreasing the absolute value of the geomagnetic latitude. On the other hand, a wind which is poleward in the morning time periods decreases $\mathrm{hmF} 2$, causing an increase in the loss rate of $\mathrm{O}^{+}\left({ }^{4} \mathrm{~S}\right)$ ions at $\mathrm{hmF} 2$, a decrease in $\mathrm{NmF} 2$, and helps to create an increase in $\mathrm{T}_{e}$.

A decrease in the production rate of $\mathrm{O}^{+}$ions by solar radiation caused by a solar zenith angle increase results in a $\mathrm{NmF} 2$ decrease with time during an evening time period, and a feebly marked evening $\mathrm{T}_{e}$ peak is created by this evening decrease of $\mathrm{N}_{e}$. A poleward wind forces the $\mathrm{F} 2$ layer to descend to low altitudes of heavy chemical $\mathrm{O}^{+}\left({ }^{4} \mathrm{~S}\right)$ ion losses, reducing $\mathrm{N}_{e}$ to low values before sunset. Due to this poleward wind, the evening $\mathrm{NmF} 2$ decrease in time becomes strong, producing a strongly pronounced decrease in the thermal electron cooling rate and the resulting increase in the evening $\mathrm{T}_{e}$ peak. The decrease in the absolute value of the geomagnetic latitude leads to the weakening of the effect of the plasma drift due to the neutral wind on $\mathrm{N}_{e}$, causing the weakening of this effect on $\mathrm{T}_{e}$ and the decrease of the magnitude or disappearance of the peak in $\mathrm{T}_{e}$.

It is found that the weakening of $\mathrm{E}_{\Lambda}$ by a factor of 10 leads to the disappearance of the morning peak in $\mathrm{T}_{e}$ over the Manila sounder and to the decrease in the magnitude of the morning peak in $\mathrm{T}_{e}$ over the Yamagawa, Okinawa, Chung-Li, Manila, Vanimo, and Darwin sounders. The evening peak in $\mathrm{T}_{e}$ is slightly less pronounced over the Darwin and Yamagava sounders due to the weakening of $\mathrm{E}_{\Lambda}$ by a factor of 10 , and this weakening of $E_{\Lambda}$ leads to the disappearance of the evening $\mathrm{T}_{e}$ peak on 20-21 March over the Akita sounder due to a decrease in the daytime $\mathrm{NmF} 2$ and an increase in the evening NmF2.

It is shown that the use of the middle-latitude time dependent model of the ionosphere and plasmasphere, which does not take into account the $\boldsymbol{E} \times \boldsymbol{B}$ plasma drift, leads to noticeable errors in the calculated daytime $\mathrm{N}_{e}$ and $\mathrm{T}_{e}$ of the $\mathrm{F} 2$ region and a part of the topside ionosphere, even at geomagnetic latitudes of about $25^{\circ}-30^{\circ}$.
Acknowledgements. The MU radar belongs to and is operated by RASC. Hourly critical frequencies fof 2 , foE and maximum usable frequency parameters M(3000)F2 data from the ionospheric sounder stations were provided by the National Geophysical Data Center, Boulder, Colorado. A.V. Pavlov was supported by grant 02-05-64204 from the Russian Foundation for Basic Research. The authors would like to thank referees for their comments on the paper, which have assisted in improving the final version.

Topical Editor M. Lester thanks B. Emery and N. Balan for their help in evaluating this paper

\section{References}

Abdu, M. A.: Major phenomena of the equatorial ionospherethermosphere system under disturbed conditions, J. Atmos., Terr., P., 59, 1505-1519, 1997.

Abdu, M. A.: Outstanding problems in the equatorial ionospherethermosphere electrodynamics relevant to spread F, J. Atmos. SP., 63, 869-884, 2001.

Anderson, D. N.: Modeling the ambient, low-latitude F-region ionosphere - A review, J. Atmos. P., 43, 753-762, 1981.

Bailey, G. J. and Balan, N.: A low-latitude ionosphereplasmasphere model, in Handbook of Ionospheric Models, edited by R. W. Schunk, pp. 173-206, Utah State Univ., Logan, Utah, 1996.

Balan, N., and Bailey, G. J.: Equatorial plasma fountain and its effects: Possibility of an additional layer, J. Geophys. Res., 100, 21 421-21 432, 1995.

Balan, N., Bailey, G. J., Subbarao, K. S. V., Abdu, M. A., and Rao, P. B.: Model comparisons of equatorial plasma fountain and equatorial anomaly at three locations, Adv. Space R., 18 (6), 69-78, 1996.

Balan, N., Bailey, G. J., Abdu, M. A., Oyama, K. I., Richards, P. G., MacDougall, J., and Batista, I. S.: Equatorial plasma fountain and its effects over three locations: Evidence for an additional layer, the $F_{3}$ layer, J. Geophys. Res., 102, 2047-2056, 1997a.

Balan, N., Otsuka, Y., and Fukao, S.: New aspects in the annual variation of the ionosphere observed by the MU radar, Geophys. Res. L., 24, 2287-2290, 1997 b.

Balan, N., Otsuka, Y., Bailey, G. J., and Fukao, S.: Equinoctial asymmetries in the ionosphere and thermosphere observed by the MU radar, J. Geophys. Res., 103, 9481-9496, 1998.

Dudeney, J. R.: The accuracy of simple methods for determining the height of the maximum electron concentration of the F2-layer from scaled ionospheric characteristics, J. Atmosph. Terr. Phys., 45, 629-640, 1983.

Fejer, B. G.: F-region plasma drifts over Arecibo - Solar cycle, seasonal, and magnetic activity effects, J. Geophys. Res., 98, 13 645-13 652, 1993.

Fejer, B. G. and Scherliess, L.: On the variability of equatorial Fregion vertical plasma drifts, J. Atmosph. Sol. Terr. Phys., 63, 893-897, 2001.

Fukao, S., Sato, T., Tsuda, T., Yamamoto, M., Yamanaka, M. D., and Kato, S.: New capabilities and system calibrations, Radio Sci., 25, 477, 1990.

Fukao, S., Onishi, Y., Tsuda, T., Yamamoto, M., Kato, S., Oliver, W. L., Takami, T., and Sato, T.: F-region seasonal behavior as measured by the MU radar, J. Atmosph. Terr. Phys., 53, 599-618, 1991. 
Hedin, A. E.: MSIS-86 thermospheric model, J. Geophys. Res., 92, 4649-4662, 1987.

Hedin, A. E., Spencer, N. W., Biondi, M. A., Burnside, R. G., Hernandez, G., and Johnson, R. M.: Revised global model of thermosphere winds using satellite and ground-based observations, J. Geophys. Res., 96, 7657-7681, 1991.

McClure, J. P.: Diurnal variation of neutral and charged particle teperatures in the equatorial F-region, J. Geophys. Res., 74, 279 291, 1969.

McClure, J. P.: Thermospheric temperature variations inferred from incoherent scatter observations, J. Geophys. Res., 76, 31063117, 1971.

Moffett, R. J.: The equatorial anomaly in the electron distribution of the terrestrial F-Region, Fundamentals of Cosmic Physics, 4, 313-391, 1979.

Oliver, W. L., Fukao, S., Takami, T., Yamamoto, M., Tsuda, T.: Thermospheric meridional winds measured by the middle and upper atmosphere radar, J. Geophys. Res., 95, 7683-7692, 1990.

Otsuka, Y., Kawamura, S., Balan, N., Fukao, S., and Bailey, G. J.: Plasma temperature variations in the ionosphere over the middle and upper atmosphere radar, J. Geophys. Res., 103, $20705-$ 20713, 1998.

Oyama, K.-I., Balan, N., Watanabe, S., Takahashi, T., Isoda, F., Bailey, G. J., and Oya, H.: Morning overshoot of $\mathrm{T}_{e}$ enhanced by downward plasma drift in the equatorial topside ionosphere, J. Geomagn. Geoelectr., 48, 959-973, 1996.

Pavlov, A. V.: New electron energy transfer rates for vibrational excitation of $\mathrm{N}_{2}$, Ann. Geophysic., 16, 176-182, 1998a.

Pavlov, A. V.: New electron energy transfer and cooling rates by excitation of $\mathrm{O}_{2}$, Ann. Geophysic., 16, 1007-1013, 1998b.

Pavlov, A. V.: New method in computer simulations of electron and ion densities and temperatures in the plasmasphere and lowlatitude ionosphere, Ann. Geophysic., 21, 1601-1628, 2003.

Pavlov, A. V., and Berrington, K. A.: Cooling rate of thermal electrons by electron impact excitation of fine structure levels of atomic oxygen, Ann. Geophysic., 17, 919-924, 1999.

Picone, J. M., Hedin, A. E., Drob, D. P., and Aikin, A. C.: NRLMSISE-00 empirical model of the atmosphere: statistical comparisons and scientific issues, J. Geophys. Res., 107(A12), 1468, doi:10.1029/2002JA009430, 2002.

Richards, P. G., Fennelly, J. A., and Torr, D. G.: EUVAC : a solar EUV flux model for aeronomical calculations, J. Geophys. Res., 99, 8981-8992, 1994 (Correction in J. Geophys. Res., 99, 13283 , 1994.)
Richmond, A. D., and Lu, G.: Upper-atmospheric effects of magnetic storms: a brief tutorial, J. Atmosph. Terr. Phys., 62, 1115$1127,2000$.

Rishbeth, H. and Garriot, O.: Introduction to ionospheric physics, New York, Academic Press, 1969.

Rishbeth, H.: Thermospheric winds and the F-region: A review, J. Atmos. Terr. Phys., 34, 1-47, 1972.

Rishbeth, H.: The equatorial F-layer: progress and puzzles, Ann. Geophys., 18, 730-739, 2000.

Rishbeth, H., and Fukao, S.: A review of MU radar observations of the thermosphere and ionosphere, J. Geomagn. Geoelectr., 47, 621-637, 1995.

Sato, T., Fukao, S., Tsuda, T., Ito, A., and Oliver, W. L.: Ionospheric incoherent scatter measurements with the middle and upper atmosphere radar- techniques and capability, Radio Science, 24, 85-98, 1989.

Scherliess, L. and Fejer, B. G.: Radar and satellite global equatorial F-region vertical drift model, J. Geophys. Res., 104, 6829-6842, 1999.

Shimazaki, T.: World-wide variations in the height of the maximum electron density of the ionospheric F2 layer, J. Radio Res. Labs. Japan, 2(7), 85-97, 1955.

Souza, J. R., Abdu, M. A., Batista, I. S. Bailey, G. J.: Determination of vertical plasma drift and meridional wind using the Sheffield University Plasmasphere Ionosphere Model and ionospheric data at equatorial and low-latitudes in Brazil: Summer solar minimum and maximum conditions, J. Geophys. Res., 105, 12 813-12 821, 2000.

Su, Y. Z., Oyama, K.-I., Bailey, G. J., Fukao, S., Takahashi, T. and Oya, H.: Longitudinal variations of the topside ionosphere at low-latitudes: Satellite measurements and mathematical modelings, J. Geophys. Res., 101, 17 191-17 206, 1996.

Su, Y. Z., Fukao, S., and Bailey, G. J.: Modeling studies of the middle and upper atmosphere radar observations of the ionospheric F layer, J. Geophys. Res., 102, 319-328, 1997.

Takami, T., Oliver, W. L., Richmond, A. D., and Fukao, S.: Ionospheric drift similarities at magnetic conjugate and nonconjugate locations, J. Geophys. Res., 101, 15 773-15 782, 1996.

Walker, G. O.: Longitudinal structure of the F-region equatorial anomaly - A review, J. Atmos. and Terr. Phys., 43, 763-774, 1981.

Watanabe, S. and Oyama, K.-I.: Effects of neutral wind on the electron temperature at a height of $600 \mathrm{~km}$ in the low-latitude region, Ann. Geophys., 14, 290-296, 1997. 